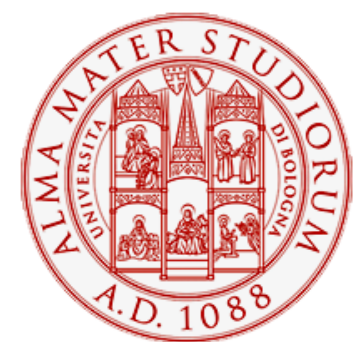

Alma Mater Studiorum - Università di Bologna DEPARTMENT OF ECONOMICS

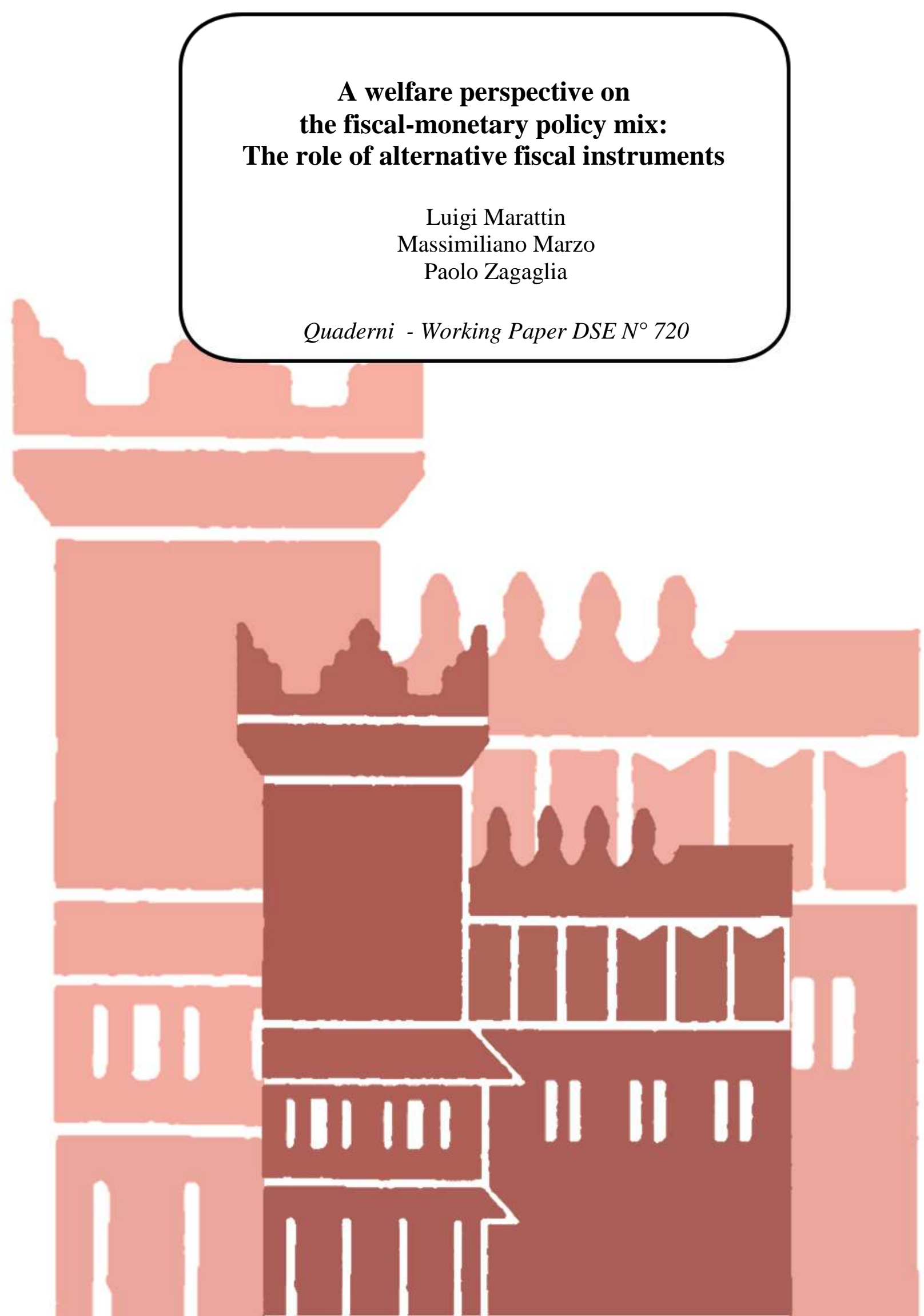




\title{
A welfare perspective on the fiscal-monetary policy mix: The role of alternative fiscal instruments
}

\author{
Luigi Marattin, Massimiliano Marzo and Paolo Zagaglia*
}

This version: November 16, 2010

\begin{abstract}
The need of fiscal consolidation is likely to dominate the policy agenda in the next decade; starting from statistical evidence on the conduct of fiscal policy in the EMU area over the last decade, this paper addresses the optimality of alternative fiscal consolidation strategies. We explore the welfare properties. In this paper we explore the welfare properties of debt-targeting fiscal policy implemented through, alternatively, distortionary taxation on consumption, labour and capital income or productive and wasteful government expenditure. We build a general equilibrium model with various distortions in order to evaluate the welfare ranking of alternative fiscal policy configurations under different monetary policy regimes. Our results show the welfare superiority of fiscal adjustments based on productive government expenditure, whereas the use of a capital income tax rate as fiscal instruments yields the highest welfare loss.
\end{abstract}

\footnotetext{
*Marattin: Department of Economics, Università di Bologna; luigi.marattin@unibo.it. Marzo: Department of Economics, Università di Bologna; massimiliano.marzo@unibo.it. Zagaglia: Modelling Unit, Sveriges Riksbank; paolo.zagaglia@riksbank.se. The views expressed herein are those of the authors only and should not be attributed to the members of the Executive Board of Sveriges Riksbank.
} 


\section{Introduction}

The process of cutting-back the massive stock of public debt accumulated after the 2008-2009 recession is likely to dominate the policy debate over the next decade. Table 1 shows the change in levels of the debt/GDP ratio in major industrialized countries from 2007 to 2010.

These figures suggest that the question is not so much whether to implement a fiscal consolidation, but rather how to do it. Specifically, whether it would be preferable to carry it out by cutting public expenditure or by increasing average tax rates on factor incomes and consumption.

The issue of whether fiscal adjustments should rely on the expenditure rather than the revenue side is hardly a new topic in the policy debate. Its importance was already emphasized by the January 2004 ECB Monthly Bulletin (p.46)

"The composition of the budgetary adjustment is particularly relevant, there being evidence that an expenditure-based adjustment tends to be more growth-friendly and long-lived than a tax-based adjustment without expenditure retrenchment."

Looking at the case-studies of Ireland and Denmark in the Eighties, Giavazzi and Pagano (1990) were the first ones to suggest that fiscal adjustments implemented on the government spending side could be expansionary. This view is confirmed by Alesina and Perotti (1997), who examine a full sample of OECD countries and find that adjustments relying on government expenditure cuts had a better chance of being successful and expansionary; on the other hand, if they are based on tax increases and cuts in public investments, tend not to be non-persistent and contractionary. This result is strengthened by Alesina and Ardagna (2009) who extend the analysis up to 2007. Using a panel OECD from 1970 to 2007, they define fiscal adjustments (stimuli) as episodes where the cyclically adjusted primary balance improves (deteriorates) by at least 1.5 per cent of GDP. Subsequently they investigate whether such episodes - that differ in size and composition - are associated with booms or recessions and with success in debt stabilization. Their conclusion is that most successful fiscal adjustments are those in which a larger share of the reduction of primary deficit is due to cuts in current spending (wage and non-wage component) and to subsidies.

Based on these considerations, in this paper we introduce a new dimension to assess the desiderability of alternative debt-stabilizing plans: what are the welfare effects (and not simply the growth effects) of fiscal adjustments based on the expenditure rather than on the revenue side? To accomplish this task, we adopt a suitable DSGE framework calibrated on the Euro area, as the focus of our analysis is mainly targeted at the EU policy debate. As we employ a workhorse for policy analysis, as the DSGE model has become, we also refer to the related rich literature on the interactions between monetary and fiscal policy.

The seminal contribution by Leeper (1991), featured by Ricardian environment and lump-sum taxation, established the parameter conditions for local equilibrium determinacy based essentially on the size of monetary policy's response to inflation. If Taylor's principle holds, determinacy is preserved regardless on fiscal policy's active or passive stance. This implies that monetary policy is conducted without any influence arising from fiscal considerations: the fiscal authority merely raises tax revenue so to balance the intertemporal budget constraint, and the dynamic of debt is the main factor determining the tax stance ${ }^{1}$. If, alternatively, monetary policy's feedback rule is not

\footnotetext{
${ }^{1}$ In many contributions that have borrowed and modified the original Leeper's framework (Sims (1994), Davig
} 
enough to affect the real interest rate, an active role of fiscal policy is needed to restore equilibrium determinacy. In particular, another strand of literature ("the fiscal theory of the price level", Woodford (1994), Sims (1994), (Canzoneri, Cumby, and Diba, 2001)) stresses the likely emergence of price level adjustments that are automatically needed in order to guarantee the intertemporal solvency of government budget constraint.

Ever since Leeper (1991) the literature began to relax some of the simplifying assumptions which were part of the original framework, in order to be able to study the interactions between fiscal and monetary policy in a richer and more realistic framework ${ }^{2}$. Basically, contributions differ insofar as they employ alternatives strategies to depart from Ricardian equivalence. One strand of literature models the presence of non-Ricardian consumers à-la Blanchard (1985), by assuming a non-zero probability of death for households (Leith and Wren-Lewis (2000), Chadha and Nolan (2007)). Under this specification, consumers'finite-horizon implies a wealth effect of government debt on aggregate consumption via the Euler equation. In this scenario C. and Thadden (2008) prove not only that steady-state government debt becomes a crucial state variable for determinacy of local equilibrium and its dynamics, but also that its level is important: the required degree of fiscal discipline is an increasing (but yet discontinuos) function of the debt level when monetary policy is to become more active ${ }^{3}$. Other contributions have broken Ricardian equivalence by introducing distortionary taxation, and have looked at the non-trivial interactions with monetary policy (Schmitt-Grohé and Uribe (2004c, 2007), Edge and Rudd (2002), Linnemann (2006)).

Our paper follows this latter approach, insofar as we introduce (multiple) distortionary taxation and implement a welfare analysis via second-order perturbation methods. Furthermore, the novelty of our contribution lies in the emphasis on the choice of the fiscal instrument. Particularly, we build a dynamic stochastic general equilibrium (DSGE) model with multiple sources of distortions, and perform a welfare evaluation of the use of different fiscal instruments. In particular, we compare the welfare properties of rules for fiscal policy that prescribe changes in different tax rates or types of government spending. Within each of these two categories, we operate a further distinction: on the spending side between government consumption and productive public spending, whereas on the revenue side between three types of distortionary taxation (on consumption, labour and capital income). Our analysis also distinguishes between monetary policy based on interest rate or money growth rules.

We obtain a number of results. We find that fiscal consolidation based on productive government expenditure (defined broadly as public spending enhancing the marginal product of capital and labour in the production function) is welfare-superior to other specifications. On the other hand, fiscal adjustment based on capital-income taxation generally bring about the highest welfare losses. These 'corners' of targeting instruments'welfare ranking seem robust to a various specifications of the interest-rate rule, and even to an alternative specifications of monetary policy

and Leeper (2005), Schmitt-Grohe and Uribe 2007, C. and Thadden (2008)), the relevant parameter of the fiscal rule is the feedback coefficient of (lump-sum) taxes on debt. The fiscal stance is passive if the coefficient is larger than the steady-state real interest rate, active otherwise. C. and Thadden (2008) note that many authors typically tighten the definition of fiscal policy to one ensuring not only the solvency of intertemporal budget constraint, but also stationarity of government debt.

${ }^{2}$ While acknowledging many significant open-economy contributions (Linnemann (2006), Leith and Wren-Lewis (2000)), we focus here on closed-economy investigations.

${ }^{3}$ Their paper also links the approach à-la-Blanchard with an alternative way to introduce non-Ricardian consumers, namely the use of credit-constrained (or "rule-of-thumb") agents (Galì, Lopez-Salido, and Vallès (2004), Bilbie (2009)). They show that the crucial qualitative results are robust to the alternative specifications. 
based on money growth. These results are not significantly reversed even if we assign a 'useful' role to government consumption, by inserting it additively into the utility function (e.g., see Linnemann and Schabert, 2004). Another relevant result concerns the ranking of (unconditional) welfare losses according to the degree of distortions in the economy. For any given fiscal instrument, the departure from perfect competition and the presence of money yields greater welfare losses than the introduction of price rigidity within a monopolistic competition framework.

We believe our result concerning the welfare-superiority of a government spending rule as fiscal instrument to be particularly relevant for daily policy-making. Recent experiences (primary UK, but also Italy although to a lesser extent) attempted to peg government spending dynamics to the evolution of macroeconomic targets. Our framework can contribute to a better understanding of the relative desiderability of such an option.

This paper is organized as follows. Section 2 presents some statistical evidence which is useful to pave the way for the normative analysis. Section 3 describes the theoretical model. Section 4 outlines the computational strategy for the solution of the model. Section 5 discusses the calibration of the model. Section 6 outlines the quantitative results. Section 7 presents some concluding remarks.

\section{Empirical Evidence}

Our theoretical question regards the welfare properties of fiscal consolidation, defined as a negative reaction of budget deficit to public debt accumulation. In this section we present our own econometric evidence regarding the plausibility of such an investigation using Euro-area aggregate quarterly data from 1999 to 2010. Particularly, in subsection 2.1. we estimate a Structural Vector AutoRegressive model in order to obtain an empirical characterization of primary deficit's movements in response to debt. In subsection 2.2. we perform a correlation analysis focused on the relationship between budget deficit's components and the stock of government liabilities.

\subsection{A SVAR Analysis on the EU area}

In this subsection we build and estimate a VAR model to illustrate the dynamics of average EU fiscal positions after a public debt shock.

The general structural form of model is given by:

$$
A_{0} X_{t}=A(L) X_{t-1}+u_{t}
$$

where $X_{t}$ is a $m \times 1$ vector of endogenous variables, $A_{0}$ is a $m x m$ matrix capturing contemporaneous relations among variables; $A(L)$ is a finite-order vector polynomial in non-negative powers of the lag operator; finally $u_{t}$ is the $m \times 1$ structural disturbance vector. Pre-multypling (1) by $A_{0}^{-1}$ we obtain the reduced form we can actually estimate:

$$
X_{t}=B(L) X_{t-1}+\xi_{t}
$$

where $B(L)=A(L) A_{0}^{-1}$ and $\xi_{t}=A_{0}^{-1} u_{t}$ is the reduced-form residual vector. 
Our first attempt consider $m=3$, so that vector $X_{t}$ is given by:

$$
X_{t}=\left[Y_{t}, D_{t}^{P R}, B_{t}\right]
$$

where $Y_{t}$ is real GDP, $D_{t}^{P R}$ is primary deficit, $B_{t}$ is real stock of government debt. All variables are seasonally-adjusted. We use quarterly EU data taken from Thomson Datastream. The sample period is 1999Q1-2010:Q1.

Identification is achieved through a standard lower-triangular Cholesky scheme, where we allow within-the-quarter effect of real activity on everything else and of primary deficit on debt.

Figure 2 shows the response of real output and deficit to a one-standard-deviation shock in government debt.

The left-hand panel shows a negative reaction of economic activity to debt-shocks, although the statistical significance ceases after 3 quarters. More interestingly, the right-hand-panel indicates that EU-aggregate primary deficit reduces after increase in the stock of government liabilities. This suggests the presence of a debt-stabilizing motive in the conduct of EU fiscal policy in the last ten years.

We test the robustness of our central result by extending to $m=4$ the dimension of vector $X$, which is now made by:

$$
X_{t}=\left[Y_{t}, D_{t}^{P R}, B_{t}, \pi_{t}\right]
$$

where $\pi_{t}$ is the CPI inflation index ${ }^{4}$. In this case we added the inflation rate which is allowed to be affected within the quarter by all other macroeconomic variables. Figure 3 displays the impulse response functions relative to this new specification. The picture confirms the negative response of primary deficit after an increase in the stock of government debt.

Our SVAR estimation seems pretty robust in indicating a debt-stabilizing motive in the conduct of fiscal policy during Euro's first decade. Before turning to a formal model to investigate the welfare properties of such a stance, we disaggregate primary deficit into the spending and the revenue component and analyze their statistical correlations with government debt.

\subsection{Correlations}

In Table 2 we report summary statistics for the main fiscal variables, seasonally adjusted. We filtered all variables by using HP filter for quarterly data, with $\lambda$ set equal to 1600 , as it usual. It is worth to note that public debt displays more volatility than public expenditure and tax revenue. This might be due to financial market effects, via interest rate changes, affecting the burden of public debt. In general, we can note a non-significant deviation from normality hypothesis for the

\footnotetext{
${ }^{4}$ Note that we cannot further extend the dimension of our VAR, given the relatively limited number of observations. This constraint, in turn, is given by our focus on the EU aggregate area.
} 
data generation process of such time series.

In Table 3 we report the autocorrelation for debt, public expenditure and tax revenue. It is immediate to note a negative autocorrelation pattern for debt for lag larger than the 4th. For tax revenue autocorrelation becomes negative right after 6 lags. Public expenditure, instead, shows a similar structure but with a much smaller decay rate than what can be observed for the other variables. In this case, the cyclical component of public expenditure appears to be short-lasting. This means that public expenditure is largely affected by trending component, due to the political economy budgeting processing.

After these preliminary statistics, let us move to the analysis of comovements between tax revenue $(T$, henceforth) and debt $(B)$ and between public expenditure $(G)$ and debt. This analysis is supporting the empirical evidence outlined in the previous subsection where we showed that primary deficit reacts negatively to government debt shocks. At this stage, we disentangle primary deficit into its two components $(G$ and $T$ ) and we look at the comovements between them and public debt at various time horizon.

Table 4 and 5 collect our results. We note that while government expenditure has a negative correlation with public debt starting from lag 2 (lag 1 is close to be zero), tax revenue displays a positive comovement, starting from lag 2.

We take these findings as a confirmation of the pattern already inferred in our structural VAR analysis: since the EMU start date (1999:1) there is evidence of a fiscal policy being conducted in order to stabilize public debt. This implies a negative (positive) response of government expenditure (tax revenue) to government debt. The rest of this paper aims to investigate the welfare consequences of such fiscal stance.

\section{The model}

We build a New Keynesian DSGE model with a number of imperfections: monopolistic competition, quadratic price-adjustment costs, transaction costs for money holding, and multiple distortionary taxation. There are infinitely-live households on the demand side and two sectors on the supply-side: one producing intermediate goods by means of capital and labour - and the other a final good, obtained by assembling all intermediate goods. The homogenous final good can be used for private and public consumption, investment and productive government expenditure. The policy side is composed by a fiscal and monetary authorities. The former acts by moving either tax rates or government expenditures in response to the stock of public debt, while the latter follows either interest rate or money-growth policy rules.

\subsection{Households}

The demand side of the economy is populated by a measure of consumers indexed by $j \in \omega_{1}$. Each agent enjoys utility from current consumption $c_{j t}$ and disutility from hours worked $\ell_{j t}$. The 
history of events $s^{t}=\left\{s_{0}, \ldots s_{t}\right\}$ up to date $t$ is attached a time- 0 probability mass $\mu\left(s^{t}\right)$. The uncertainty in the choice process is summarized by the conditional-expectation operator $E_{0}[\cdot]:=$ $\sum_{s^{t+1}} \mu\left(s_{t+1} \mid s^{t}\right)$. Given this structure, the household $j$ 's allocation problem takes the form:

$$
\max _{\left\{c_{j t}, \ell_{j t}, M_{j t}, D_{j t}\right\}_{t=0}^{\infty}} \mathrm{E}_{0}\left[\sum_{t=0}^{\infty} \beta^{t} \mathcal{U}_{j}\left(c_{j t}, \ell_{j t}\right)\right]
$$

with the intertemporal discount factor $\beta \in(0,1)$, and subject to the budget constraint:

$$
\begin{aligned}
\left(1+\tau_{t}^{c}\right) P_{t}[1 & \left.+\psi_{t} \mathcal{M}\left(V_{j t}\right)\right] c_{j t}+M_{j t}+D_{j t}+P_{t} i_{j t} \\
& \leq\left(1-\tau_{t}^{\ell}\right) P_{t} w_{j t} \ell_{j t}+P_{t}\left[\left(1-\tau_{t}^{k}\right) r_{t}+\tau_{t}^{k} \delta\right] k_{j t}+R_{t-1} D_{j t-1}+M_{j t-1}+\Pi_{j t}
\end{aligned}
$$

Money is a choice variable in this model, and enters the household's budget constraint both directly and indirectly. The indirect channel arises from the presence of transaction costs in the product markets. In order to purchase an amount $P_{t} c_{j t}$ of consumption goods, the consumer faces an additional expenditure of $P_{t} c_{j t} \psi_{t} M\left(V_{j t}\right)$. The transaction cost function $M\left(V_{j t}\right): R_{+} \rightarrow R_{+}$ depends on the velocity of money:

$$
V_{j t}:=\frac{P_{t} c_{j t}}{M_{j t}}
$$

The additional term $\psi_{t}$ indicates a multiplicative transaction cost shock:

$$
\ln \left[\psi_{t+1}\right]=\rho_{\psi} \ln \left[\psi_{t}\right]+\left(1-\rho_{\psi}\right) \ln [\bar{\psi}]+\sigma_{\psi} \epsilon_{t+1}^{\psi}
$$

with $\epsilon_{t}^{\psi} \sim N(0,1)$.

The portfolio of financial assets includes government bonds $D_{j t}$ and claims $\omega_{j \iota}$ on the profits of the monopolistically-competitive firms. The gross interest rate on bonds is denoted as $R_{t}$. Let $\Pi_{j \iota t}$ denote the dividend stream generated by firm $\iota$ and appropriated by household $j$. The total dividend payment for household $j$ is:

$$
\Pi_{j t}:=\int_{\iota \in \omega_{2}} \omega_{j \iota} \Pi_{\iota t} d \iota
$$

For the sake of analytical simplicity, we assume that the allocation of ownership shares across agents is constant, and beyond the control of households.

Consumers control the evolution of the individual-specific capital stock $k_{j t}$ through their individual decisions on investment $i_{j t}$. Idiosyncratic capital is rented to the firms of the intermediate-good sector at the rate $r_{t}$. The accumulation of capital takes place according to a standard linear law of motion:

$$
k_{j t+1}=i_{j t}+(1-\delta) k_{j t}
$$

Three types of distortionary taxes enter the consumer's budget constraint. There are taxes on consumption, labor income, and capital income at the average rates $\tau_{t}^{c}, \tau_{t}^{\ell}$ and $\tau_{t}^{k}$ respectively. Consumption taxes enter as indirect taxes. Capital taxes are imposed on the real return of capital, 
rather than on nominal returns. Following Kim and Kim (2003a), we introduce a depreciation allowance on capital taxation, and $r_{t}$ is the rental rate of capital.

\subsection{The final-good sector}

The firms in the final-good sector are mere retailers. They face a perfectly competitive product market. Their production function consists of a Dixit-Stiglitz technology that aggregates intermediate goods:

$$
y_{t} \leq\left[\int_{\iota \in \omega_{2}} y_{\iota t}^{\frac{\theta-1}{\theta}} d \iota\right]^{\frac{\theta}{\theta-1}}
$$

The demand for each intermediate good $y_{\iota t}$ follows from the static profit maximization problem:

$$
\max _{\left\{y_{\iota t}\right\}_{\iota \in \omega_{2}}} P_{t}\left[\int_{\iota \in \omega_{2}} y_{\iota t}^{\frac{\theta-1}{\theta}} d \iota\right]^{\frac{\theta}{\theta-1}}-\int_{\iota \in \omega_{2}} \mathcal{P}_{\iota t} y_{\iota t} d \iota
$$

and takes the form:

$$
y_{\iota t}=\left[\frac{\mathcal{P}_{\iota t}}{P_{t}}\right]^{-\theta} y_{t}
$$

The price index of final goods can be derived as:

$$
P_{t}=\left[\int_{\iota \in \omega_{2}} \mathcal{P}_{\iota t}^{1-\theta} d \iota\right]^{\frac{1}{1-\theta}}
$$

\subsection{The intermediate-good sector}

In the intermediate sector, firm $\iota \in \omega_{2}$ uses capital and output as production inputs according to a constant returns-to-scale technology:

$$
y_{\iota t} \leq z_{t} k_{\iota t}^{\alpha} \ell_{\iota t}^{1-\alpha}\left(g_{t}^{p}\right)^{\zeta}
$$

where $z_{t}$ is an exogenous stationary productivity shock:

$$
\ln \left[z_{t+1}\right]=\rho_{z} \ln \left[z_{t}\right]+\left(1-\rho_{z}\right) \ln [\bar{z}]+\sigma_{z} \epsilon_{t+1}^{z}
$$

and $\epsilon_{t}^{z} \sim N(0,1)$. I introduce nominal price rigidity in the form of quadratic price-adjustment costs:

$$
\mathcal{C}\left(\mathcal{P}_{\iota t}\right):=\frac{\phi_{p}}{2}\left(\frac{\mathcal{P}_{\iota t}}{\mathcal{P}_{\iota t-1}}-\bar{\pi}\right)^{2} y_{t}
$$

where $\bar{\pi}$ denotes steady-state inflation. This specification differs from the standard menu cost approach of Rotemberg (1982), whereby firms face costs for changing prices independently from the size of the change itself. In equation 15 , only price changes that deviate from the steady state are costly. Ireland (2001) shows that adding a lag structure to equation 15 is key to generating a realistic degree of inflation persistence on US data. Smets and Wouters (2003) instead adopt 
a Calvo (1983)-style setting. They assume that only a random fraction of firms can re-set prices according to the optimal price index. Under quadratic adjustment costs, all firms can change their pricing policies as the costs of price stickiness become prohibitive.

The problem of firm $\iota$ involves choosing prices and quantities such that expected profits are maximized:

$$
\max _{\left\{\mathcal{P}_{\iota t}, \ell_{\iota t}, k_{\iota t}\right\}_{t=0}^{\infty}} \mathrm{E}_{0}\left[\sum_{j=0}^{\infty} \Xi_{t+j}\left(\frac{\mathcal{P}_{\iota t}}{P_{t}} y_{\iota t}-w_{t} \ell_{\iota t}-r_{t} k_{\iota t}-\mathcal{C}\left(\mathcal{P}_{\iota t}\right)\right)\right]
$$

subject to the constraints 11 and 13 .

\subsection{Fiscal policy rules}

The government faces a standard flow budget constraint:

$$
\int_{j \in \omega_{1}} D_{j t} d j+P_{t} \tau_{t}+\int_{j \in \omega_{1}} M_{j t} d j=R_{t-1} \int_{j \in \omega_{1}} D_{j t-1} d j+P_{t} g_{t}+\int_{j \in \omega_{1}} M_{j t-1} d j
$$

Real total taxation is denoted as $\tau_{t}$, and $g_{t}$ indicates total government spending. The government issues one-period riskless (non-contingent) nominal bonds denoted by $D_{t}$. Total revenues from taxation are decomposed into consumption taxes $\tau_{t}^{c}$, capital taxes $\tau_{t}^{k}$ and labor taxes $\tau_{t}^{\ell}$ :

$$
\tau_{t}:=\tau_{t}^{c} \int_{j \in \omega_{1}} C_{j t}\left[1+\psi_{t} \mathcal{M}\left(V_{j t}\right)\right] d j+\tau_{t}^{k} \int_{j \in \omega_{1}}\left(r_{t}-\delta\right) K_{j t} d j+\tau_{t}^{\ell} \int_{j \in \omega_{1}} w_{j t} \ell_{j t} d j
$$

The literature on public finance provides plenty of results of equivalence between different types of taxes in terms of economic impact. However, these results arise in static models that include only a limited number of frictions, and it is doubtful whether these kinds of equivalence can be reproduced in the present framework. Total public spending is composed by a pure consumption $c$ and a productive $p$ part:

$$
g_{t}:=\int_{\iota \in \omega_{2}} g_{t}^{p}+\int_{j \in \omega_{1}} g_{t}^{c}
$$

We also specify the intertemporal budget constraint of the government:

$$
\begin{aligned}
R_{t} \int_{j \in \omega_{1}} D_{j t} d j \leq \sum_{p=0}^{\infty} \mathrm{E}_{t+p}\left(\frac{1}{R_{t+p}}\right)^{p}\left[\int_{j \in \omega_{1}} M_{j t+p} d j\right. & \\
& \left.\quad-\int_{j \in \omega_{1}} M_{j t-1+p} d j+P_{t+p} \tau_{t+p}-P_{t+p} g_{t+p}\right]
\end{aligned}
$$

This amounts to saying that the maximum level of outstanding debt in every period should not exceed the discounted sum of seignorage revenues and primary surpluses. Although not emerging from the notation, the intertemporal budget constraint should hold for every realization of the stochastic shocks. This result is due to Bohn (1995), who shows that economies that fall short of this requirement need not ensure sustainable debt policies.

This paper is concerned with the business cycle costs of the operation of fiscal policy. Hence, 
specifying the way fiscal policy works off the steady state is a crucial. Two views are often put forward, and are presented in the next two subsections.

\subsection{Targeting through taxation}

The Monthly Bulletin of the ECB for January 2004 reviews the conduct of fiscal policy in the EMU area. The interpretation of the events of the transition period towards the Single Currency is especially revealing (see page 44 ):

"(T)he major consolidation efforts undertaken between the early 1990s and 1997 suggest that the signing of the Maastricht Treaty and the adoption of the EU fiscal framework successfully promoted fiscal discipline during that period. However, consolidation was largely based on revenue increases, while primary expenditure rose slightly on average in the euro area."

This hints to a scenario where public spending is strongly exogenous. Standard real business cycle models include sources of government spending in the form of autoregressive process. For reasons that will be made clear in section 5.2, we assume that both productive and unproductive public expenditures are fixed to their steady state levels. The average tax rate is instead set to bring about the required consolidation.

We assume that total taxation evolves according to an iso-elastic function of the ratio between current and steady-state fiscal deficit. Recent papers like Schmitt-Grohé and Uribe (2007) and Railavo (2004) propose fiscal reaction rules of an error-correction type. Full adjustment towards the fiscal target takes place in a few quarters in those rules. Our formulation intends to capture the more plausible idea of slow and persistent changes in taxation. Coherently with both the establishment of the Maastricht Treaty, and the theoretical literature on fiscal policy rules, we consider public debt- targeting.

The model includes average tax rates on consumption, labour and capital income. From an operational point of view, these are the three instruments that the government can employ. Since we aim at disentangling the effects of adjusting different tax rates, we consider one average tax rate as a policy variable at a time. For instance, after fixing the tax rates on both labour income and consumption at their steady state levels, we assume that the tax rate on capital income is endogenous according to the policy rule:

$$
\frac{\tau_{t}^{k}\left(r_{t}-\delta\right) k_{t}}{\bar{\tau}^{k}(\bar{r}-\delta) \bar{k}}=\left[\frac{d_{t-1}}{\bar{d}}\right]^{\nu_{1}}
$$

where lower-case letters are variables in real terms, variables with upper bars are evaluated at the steady state, and $\nu_{1} \geq 0$.

The question arises as to whether this simple rule fulfills the intertemporal budget constraint of the government. The answer is a positive one, on the condition that we restrict our attention to equilibria where all the real variables are bounded in a small neighborhood of the steady state. Only in this case tax rules of the form of equation 20 not raise any problem. Another way of looking at the issue is that, in equilibrium, the government sector and the private sector are mirror images of each other. This implies that imposing the government's intertemporal budget constraint substitutes for the usual transversality condition in the consumer's optimization problem 
in equilibrium. Then, the issue is whether the transversality constraint is satisfied, and the same logic applies.

\subsection{Targeting through public spending}

The ECB Monthly Bulletin for January 2004 also addresses the strategies of fiscal consolidation undertaken by the Member States since 1998 (see p. 46):

"Public finance developments thus present at best a mixed picture since 1998. (...) Again, on average in the euro area, no significant expenditure restraint was exercised. These developments are largely responsible for the fact that the average deficit for the euro area is estimated to have been close to $3 \%$ of GDP in 2003, with some countries in excessive deficit."

The assessment continues on page 48:

"(S)trategies changed in many countries as regards revenue but not as regards expenditure policies. (...) Concerns about the distortionary effects of heavy taxes on incentives $(. .$.$) led to a policy strategy giving priority to tax cuts over the need for$ budgetary discipline."

In other words, the ECB supports the view for which successful fiscal consolidations should be financed through primary spending cuts.

In this scenario, the average tax rates of consumption, capital and labor income are fixed at their steady-state levels. The policy prescription outlined above requires me to re-define the baseline rule along the lines of 20 . When government consumption is the instrument for fiscal restraints, $g_{t}^{p}$ is capped at the steady state, and:

$$
\frac{g_{t}^{c}}{\bar{g}^{c}}=\left[\frac{d_{t-1}}{\bar{d}}\right]^{\nu_{1}}
$$

with $\nu_{1} \leq 0$. Public spending is thus fully controllable by the government, and takes up the duty of accomodating the changes in revenues due to exogenous shocks.

\subsection{Equilibrium and aggregation}

Definition 1 A symmetric monopolistically-competitive equilibrium consists of stationary sequences of prices:

$$
\left\{\mathbf{P}_{\mathbf{t}}\right\}_{t=0}^{\infty}:=\left\{P_{t}^{*}, R_{t}^{*}, w_{t}^{*}, r_{t}^{*}\right\}_{t=0}^{\infty}
$$

real quantities:

$$
\begin{aligned}
& \left\{\mathcal{Q}_{\mathbf{t}}\right\}_{t=0}^{\infty}:=\left\{\left\{\mathcal{Q}_{t}^{h}\right\}_{t=0}^{\infty},\left\{\mathcal{Q}_{t}^{f}\right\}_{t=0}^{\infty},\left\{\mathcal{Q}_{t}^{g}\right\}_{t=0}^{\infty}\right\} \\
& \left\{\mathcal{Q}_{t}^{h}\right\}_{t=0}^{\infty}:=\left\{c_{t}^{*}, \ell_{t}^{*}, k_{t+1}^{*}, i_{t}^{*}, m_{t}^{*}, d_{t}^{*}\right\}_{t=0}^{\infty} \\
& \left\{\mathcal{Q}_{t}^{f}\right\}_{t=0}^{\infty}:=\left\{y_{t}^{*}, k_{t}^{*}, \ell_{t}^{*}\right\}_{t=0}^{\infty} \\
& \left\{\mathcal{Q}_{t}^{g}\right\}_{t=0}^{\infty}:=\left\{g_{t}^{c *}, g_{t}^{p *}, \tau_{t}^{c *}, \tau_{t}^{k *}, \tau_{t}^{\ell *}, m_{t}^{*}, d_{t}^{*}\right\}_{t=0}^{\infty}
\end{aligned}
$$


and exogenous shocks:

$$
\left\{\mathcal{E}_{t}\right\}_{t=0}^{\infty}:=\left\{\epsilon_{t}^{z}, \epsilon_{t}^{\psi}\right\}_{t=0}^{\infty}
$$

that aggregate over $\omega_{1}=[0,1]$ and $\omega_{2}=[0,1]$, that are bounded in a neighborhood of the steady state, and such that:

(i) given prices $\left\{\mathbf{P}_{\mathbf{t}}\right\}_{t=0}^{\infty}$ and shocks $\left\{\mathcal{E}_{t}\right\}_{t=0}^{\infty},\left\{\mathcal{Q}_{t}^{h}\right\}_{t=0}^{\infty}$ is a solution to the representative household's problem;

(ii) given prices $\left\{\mathbf{P}_{\mathbf{t}}\right\}_{t=0}^{\infty}$ and shocks $\left\{\mathcal{E}_{t}\right\}_{t=0}^{\infty},\left\{\mathcal{Q}_{t}^{f}\right\}_{t=0}^{\infty}$ is a solution to the representative firms' problem;

(iii) given quantities $\left\{\mathbf{Q}_{\mathbf{t}}\right\}_{t=0}^{\infty}$ and shocks $\left\{\mathcal{E}_{t}\right\}_{t=0}^{\infty},\left\{\mathbf{P}_{\mathbf{t}}\right\}_{t=0}^{\infty}$ clears the market for goods, factors of production, money and bonds:

$$
\begin{aligned}
& y_{t}^{*}=\int_{j \in \omega_{1}}\left[1+\psi_{t} \mathcal{M}\left(V_{t}^{*}\right)\right] c_{t}^{*} d j+\int_{j \in \omega_{1}} i_{t}^{*} d j+g_{t}^{*}+\int_{\iota \in \omega_{2}} \mathcal{C}\left(P_{t}^{*}\right) d \iota \\
& k_{t}^{*}=\int_{\iota \in \omega_{2}} k_{t}^{*} d \iota=\int_{j \in \omega_{1}} k_{t}^{*} d j \\
& \ell_{t}^{*}=\int_{\iota \in \omega_{2}} \ell_{t}^{*} d \iota=\int_{j \in \omega_{1}} \ell_{t}^{*} d j \\
& m_{t}^{*}=\int_{j \in \omega_{1}} m_{t}^{*} d j \\
& d_{t}^{*}=\int_{j \in \omega_{1}} d_{t}^{*} d j
\end{aligned}
$$

(iv) given quantities $\left\{\mathbf{Q}_{\mathbf{t}}\right\}_{t=0}^{\infty}$, prices $\left\{\mathbf{P}_{\mathbf{t}}\right\}_{t=0}^{\infty}$ and shocks $\left\{\mathcal{E}_{t}\right\}_{t=0}^{\infty},\left\{\mathcal{Q}_{t}^{g}\right\}_{t=0}^{\infty}$ and satisfy the flow budget constraint of the government;

(v) fiscal policy is set according to one of the processes for either $\tau_{t}^{*}$ or $g_{t}^{*}$ described in section 3;

(vi) the central bank sets the nominal interest rate according to a simple policy rule.

\section{Computations}

Since the aim of this work is to characterize the costs of arrangements of monetary and fiscal policy, special care needs to be put on the welfare calculations. To that end, solution methods based on first-order approximations of the optimality conditions of the model have been shown to yield inaccurate results (see Schmitt-Grohé and Uribe, 2007; Kim and Kim, 2003b).

Woodford (2003, chap. 6) shows that a first-order solution is welfare-accurate only if the deterministic steady states is equivalent coincides with the first-best equilibrium. This condition breaks down along several directions. Distortionary labor taxation prevents long-term employment from reaching the level that would be achieved in a fully competitive setting. The introduction of subsidies for removing the bias arising from the monopoly power in the intermediate sector is disregarded. Also, the stylized economy is characterized by transaction frictions that give rise to a positive demand for money at the steady state. 


\subsection{Local validity of approximation}

Second-order perturbation methods are defined only around small neighborhoods of the approximation points, unless the approximated function is globally analytic (see Anderson, Levin, and Swanson, 2004). Since the conditions for an analytic form of the policy function are hardly establishable, the problem of validity of the Taylor expansion remains. I approach this issue at different levels. First, we calibrate the processes for exogenous shocks in such a way that their fluctuations are constrained within small intervals (see also Schmitt-Grohé and Uribe, 2007). Second, we impose ad hoc bounds that restrict the stochastic steady states of some variables to be arbitrarily close to their deterministic counterparts.

Kollmann (2003) raises the issue of providing appropriate bounds for the fluctuations of public debt. There are both technical and economic reasons for that. Coherently with historical evidence on industrialized countries, the model should generate a dynamics of financial assets such that the government is a net debtor in the long run. Following Kollmann (2003), we consider only rational-expectations equilibria that fulfill the following constraint enforced ex-post:

$$
\left|\mathrm{E}\left[\hat{d}_{t}\right]\right|<0.01
$$

where the hat denotes the deviation from the steady state. This means that the long-run value of real public debt is constrained around the non-stochastic steady state.

We also impose a zero lower bound on nominal interest rates:

$$
\mathrm{E}\left[R_{t}\right]>\kappa \sigma_{\hat{R}_{t}}
$$

with a constant $\kappa$, and $\sigma_{\hat{R}_{t}}$ as the unconditional variance of $\hat{R}$. This constraint rules out policies that are excessively aggressive. The reason is that large deviations of the nominal rate of interest from the steady state are likely to prescribe violations of the zero bound at some point in time. This type of limit on interest rates is admittedly tighter than that of Schmitt-Grohé and Uribe (2004b) over the regions with $\mathrm{E}\left[R_{t}\right]<\bar{R}$.

\subsection{Welfare evaluation}

According to the second-order approximation of the policy function, aggregate welfare is defined as the expected lifetime utility conditional on the initial distribution of state variables $s_{0}$ :

$$
\begin{aligned}
\mathcal{W}_{0}:=\mathrm{E}\left[\sum_{t=0}^{\infty} \beta^{t} \mathcal{U}_{j}\left(s_{j t}\right) \mid s_{0} \sim(\underline{s}, \underline{\Omega})\right] \\
\simeq \frac{\mathcal{U}_{j}(\bar{s})}{1-\beta}+\left[\begin{array}{ll}
\nabla \mathcal{U}_{j}(\bar{s}) & \frac{1}{2} \operatorname{vec}\left(\nabla^{2} \mathcal{U}_{j}(\bar{s})\right)^{\prime}
\end{array}\right]\left[\Theta_{1}\left(\begin{array}{c}
\underline{s} \\
\operatorname{vec}\left(\underline{\Omega}+\underline{s} \underline{s}^{\prime}\right)
\end{array}\right)+\Theta_{2} \sigma^{2}\right]
\end{aligned}
$$

where $\underline{s}$ and $\underline{\Omega}$ are, respectively, the mean and the covariance matrix of the distribution of the initial state of the economy, and $\Theta_{1}$ and $\Theta_{2}$ are suitable matrices.

An alternative to the conditional welfare level is represented by the unconditional expected 
instantaneous utility:

$$
\mathcal{W}:=\mathrm{E}\left[\mathcal{U}_{j}\left(s_{t}\right)\right] \simeq \mathcal{U}_{j}(\bar{s})+\left[\nabla \mathcal{U}_{j}(\bar{s}) \quad \frac{1}{2} \operatorname{vec}\left(\nabla^{2} \mathcal{U}_{j}(\bar{s})\right)^{\prime}\right] \Theta_{3} \sigma^{2}
$$

This unconditional welfare index disregards the transition costs arising from moving from one steady state to another, and has been argued to produce incorrent welfare rankings (see Kim, 2003). Thus, correction-bias methods have been proposed to avoid the occurrence of 'spurious welfare results' (see Kim and Kim, 2003b and Sutherland, 2002). Both the conditional and the unconditional welfare levels are computed using the formulas presented in Paustian (2003).

In order to compare the outcomes of different policies, we compute the permanent change in consumption, relative to the steady state, that yields the expected utility level of the distorted economy. Given steady states of consumption $\bar{c}^{l}$ and hours worked $\bar{\ell}$ of the model $\iota$, this translates into the number $\Delta_{c}^{\iota}$ such that:

$$
\sum_{t=0}^{\infty} \beta^{t} \mathcal{U}_{j}^{\iota}\left(\left[1+\Delta_{c}^{\iota}\right] \bar{c}_{j}^{\iota}, \bar{\ell}_{j}\right)=\mathcal{W}_{0}^{\iota}
$$

The interpretation of this equation goes as follows. Four elements determine the size of the welfare metric. On the right-hand side of the equality, the deterministic steady state, its stochastic counterpart, and the transition from the deterministic to the stochastic long-run equilibrium of $\iota$. On the left-hand side, instead, the deterministic steady states of the model with respect to which the current distorted economy is compared, i.e. the 'benchmark'. Since the full model of section 2 includes a large number of rigidities, disentangling the welfare impact of the sources of sluggishness requires comparing smaller models where some sources of rigidity are switched off. This generates the additional complication of comparing the welfare costs in models with different non-stochastic steady states. And the computation of the welfare costs due to pure transitional dynamics is not straightforward any longer. Two observations arise.

On the one hand, we should choose a benchmark common for all the models. On the other, in doing so, the transition between deterministic steady states enters the scene as a determinant of $\Delta_{c}^{\iota}$. Since $\bar{\ell}$ does not change across models, $\bar{c}$ is the source of the problem. The relation between deterministic steady states of consumption can be cast as:

$$
\bar{c}_{j}^{\iota}=\left[1+\varpi^{\iota}\right] \bar{c}_{j}^{b}
$$

where $\bar{c}_{j}^{b}$ accrues to the benchmark, $\bar{c}_{j}^{\iota}$ to the distorted economy $\iota$, and $\varpi^{\iota}$ is the measure of steady-state equivalent variation in consumption. The measure $\varpi_{c}^{\iota}$ of transitional welfare costs follows from the following equality:

$$
\left(1+\varpi_{c}^{\iota}\right)\left(1+\varpi^{\iota}\right) \bar{c}_{j}^{b}=\left(1+\Delta_{c}^{\iota}\right) \bar{c}_{j}^{b}
$$

Given $\varpi^{\iota}$ and $\Delta_{t}^{\iota}$, the welfare costs due to the transition between the deterministic and the stochastic steady states are captured by:

$$
\varpi_{c}^{\iota}=\frac{1+\Delta_{c}^{\iota}}{1+\varpi^{\iota}}-1
$$


Contrary to what is done in existing papers like Kollmann (2003), we cannot use the deterministic steady states as conditioning means of the initial states, for that would bias the welfare ranking of policies. Since there is no source of time inconsistency in the models, optimal policy produces the highest conditional welfare. What matters, then, is that one uses the same initial distribution across both policies and models (see Kim, 2003). We follow the practice of setting both conditioning means and conditioning covariances to zero.

Unconditional welfare costs are computed in a fashion similar to the conditional counterpart:

$$
\mathcal{U}_{j}^{\iota}\left(\left[1+\Delta_{u c}^{\iota}\right] \bar{c}_{j}^{\iota}, \bar{\ell}_{j}\right)=\mathcal{W}^{\iota}
$$

In this case, transitions between steady states do not affect the welfare index, and all the dynamics refers to instantaneous 'jumps'. When the benchmark model has steady-states different from those of the current model, the welfare costs $\varpi_{u c}^{\iota}$ due to adjusting expected utility to $\mathcal{W}^{\iota}$ are computed like in 35.

\section{Functional forms and calibration}

We assume that the felicity function $\mathcal{U}_{j}: \mathbb{R}_{+} \times[0,1] \rightarrow \mathbb{R}_{+}$is time-separable in consumption and hours worked:

$$
\mathcal{U}_{j}\left(c_{j t}, \ell_{j t}\right):=\frac{\left[\left(c_{j t}\right)^{\gamma_{1}}\left(1-\ell_{j t}\right)^{1-\gamma_{1}}\right]^{1-\gamma_{2}}-1}{1-\gamma_{2}}
$$

where $\gamma_{2}$ is the inverse of the intertemporal elasticity of consumption substitution. The transaction cost function $\mathcal{M}\left(V_{t}\right): \mathbb{R}_{+} \rightarrow \mathbb{R}_{+}$is increasing and convex with respect to money velocity. Convexity rules out the possibility of zero money demand with a positive nominal interest rate in the steady state. We borrow the following specification from Schmitt-Grohé and Uribe (2004a):

$$
\mathcal{M}\left(V_{j t}\right):=a V_{j t}+\frac{b}{V_{j t}}-2 \sqrt{a b}
$$

The implicit money-demand function from the first-order conditions takes the form:

$$
m_{t}=\left[\frac{1}{a}\left\{b+\frac{1}{\left(1+\tau_{t}^{c}\right) \psi_{t}}\left(\frac{R_{t}-1}{R_{t}}\right)\right\}\right]^{-1 / 2} c_{t}
$$

The model is calibrated on yearly data for the Euro area from 1999 to 2004. Since no standard calibration for this economy has been proposed for some of the deep parameters, we start out by taking the steady state values of some observable variables as given. On the basis of those, we compute the observables. The steady-state inflation rate is assumed to be $5 \%$ a year. The intertemporal discount factor $\beta$ of consumers resulting from the calibration is equal to 0.9926 , which is higher than what is usually assumed for yearly models. The intertemporal elasticity of substitution $1 / \gamma_{2}$ equals 0.6667 , and lies within the range of values usually assigned in the RBC literature with $\gamma_{2}$ between 1 and 3 . The weight of the consumption objective $\gamma_{1}$ for the model with money equals 0.352 . The resulting steady-state gross rate of interest is 1.0578.

For the calibration of the money-demand function, we search for a combination of $a$ and $b$ that 
produce both a money velocity, and an interest semi-elasticity of money broadly consistent with European data at the steady state. We find that values of 2.1 and 0.03 for $a$ and $b$, respectively, generate a semi-elasticity of approximately -1.67, which is within the range of the estimates of Brand and Cassola (2004) for the Euro area. However, these parameter values generate a steady-state money-income velocity of 0.51 , and overshoot the estimates of existing studies like Brand, Gerdesmeier, and Roffia (2002).

The capital share $\alpha$ of output is set equal to 0.3 , such that the steady-state fraction of labor income is approximately $70 \%$. The depreciation of capital $\delta$ is $10 \%$ a year. The ratio between capital and output at the steady state is 2.2 , which is the value proposed by Smets and Wouters (2003). The steady-state amount of labor services $\bar{\ell}$ is usually calibrated equal to $1 / 3$ based on US data. Prescott (2003) provides evidence of a sizeable wedge in the amount of market work in Germany, France and Italy with respect to the US in the 90s. Following his findings, I choose $\bar{\ell}$ equal to 0.2 .

The elasticity of substitution between differentiated labor services follows from the calibration of the average wage markup of $16 \%$ used in (see Bayoumi, Laxton, and Pesenti, 2004). The degree of monopolistic competition $\theta$ is set in such a way that the markup of prices over marginal costs is $22 \%$, which is a reliable estimate for European countries according to Bayoumi, Laxton, and Pesenti (2004). The productivity shock has the quantitative properties estimated by Smets and Wouters (2003), with a value of one at the steady state.

The steady-state ratio between total government spending and output is calibrated in such a way that the public debt-output ratio is in the range of 50-55\%. Since we compare optimal policies in smaller models without money demand, we need to adjust the calibration of the output share of public spending accordingly. The reason is that we cannot find any reasonable figures such that the ratio between debt and output is of comparable magnitude across models. We choose to adjust the fraction of government consumption $\bar{g}^{c} / \bar{y}$. The model with money can sustain a larger share of government consumption - 38.6\% - than the model without money - 30.7\% - due to the presence of seignorage revenues at the steady state. We keep the fraction of productive spending capped at 0.04. The figures for average taxation on consumption, capital and labor suggest a steady-state ratio between total taxation and output of 0.31 in models, which is in line with the empirical evidence. The average tax rates for capital, consumption and labor are taken from Kim and Kim (2003a), and are based on estimates for Germany, France and Italy. The value of the productive-spending elasticity of output $\zeta$ is taken from Andrés, López-Salido, and Vallés (2001).

We finally set the parameter $\sigma$ of the state-space representation of the model equal to 1. Finally, the zero lower-bound on nominal interest rates involves the parameter $\kappa$ set to 2 . Table 1 summarizes the calibration of the model.

Having fully dealt with those issues, we are ready to carry out the welfare analysis under several directions. First, we distinguish between interest rate and money supply specifications of the monetary policy rule; we compute welfare measures (as described in the previous section) conditional on the different tax instrument employed by the fiscal authority under both monetary policy stances. In case of interest-rate rule, we further distinguish between the cashless economy and the model with money. Furthermore, we carry out some additional robustness exercises. Determinacy issues are dealt with in Table 2, which illustrates the coverage of determinacy regions (as a percentage of grid points) under cashless and money economy. 


\section{Results}

This section contains the results of the welfare analysis. First we present the results referring to a cashless economy (both with zero and positive money demand), further distinguishing between fully-optimized policy rules and standard parametrization. Then we analyze the case of a money-growth rule. Finally, we compare the results according to the degree of distortion in the economy.

Under this first specification, we have a cashless economy and the monetary authority sets the nominal interest rate according to a standard general formulation of the Taylor rule:

$$
\hat{R}_{t}=\alpha_{R} \hat{R}_{t-1}+\alpha_{\pi} \hat{\pi}_{t}+\alpha_{y} \hat{y}_{t}
$$

where hats denote log-deviations from the deterministic steady state:

$$
\hat{x}_{t}:=\ln \left[\frac{x_{t}}{\bar{x}}\right]
$$

Table 3 reports the combinations of fully-optimized coefficients of the policy rules and the corresponding welfare metrics ${ }^{5}$. Each line identifies the parameters' combination delivering the highest welfare. Left-hand side of the table refers to the cashless economy, whereas right-hand side includes money. Starting from the former, we look at the conditional welfare measure and we notice - focusing on time varying distortionary taxation or government spending targets - that the lowest welfare loss is obtained in case of productive government spending as fiscal policy instrument, with a unit feedback coefficient in response to deviation of last-period government debt from steady-state level. The highest loss, on the other hand, is achieved when the stabilization role is beared by capital-income taxation.

Turning to the unconditional welfare measure, it is worthwhile to comment the last column's results: models with money and lump-sum taxes display a larger $\varpi^{\iota}$ than models with distortionary taxes. That's due to the fact that consumption taxes enter money demand which, in turn, determines steady-state consumption. The joint presence of positive money demand and non-distortionary taxation determines the following chain of events: no consumption taxes mean higher consumption and thus higher money velocity, which in turn causes higher money demand in equilibrium and lower 'pure' consumption for purchase of goods and services that we would have in the case of distortionary taxes. In fact, as it is evident from consumer's budget constraint, the government is not able to distinguish (and so tax differently) between consumption for pure consumer's motives, and consumption for transaction money-demand motives ${ }^{6}$. In terms of welfare evaluation, this effect counterbalances the role of money in the government budget constraint, and so determines a higher steady-state equivalent variation in consumption.

Table 4 shows the results in case of monetary policy rule coefficients set at the standard reference values, rather than subject to the grid search procedure as in the previous table. Under Taylor's parametrization $\left(\phi_{\pi}=1.5\right.$ and $\left.\phi_{y}=0.5\right)$ conditional welfare loss is lowest in case of government consumption targeting, whereas equilibrium is not determinate in case of constant tax rate, capital-income taxation or productive government spending targeting.

\footnotetext{
${ }^{5}$ In case of lump-sum taxation, the corresponding tax burdens are calibrated so to replicate the steady-state debt/output ratio than we would have in the same economies but with distortionary taxation.

${ }^{6}$ This 'myopic' behaviour of the government seems a fairly harmless assumption.
} 
Table 5 and 6 illustrate the same welfare calculations (with optimized feedback coefficients) as in Table 3 but, respectively, with no interest-rate smoothing in the Taylor rule and no debt targeting in the fiscal policy rules. Note that in the former case - which preserve our focus on fiscal targets - the welfare superiority of productive government expenditure as fiscal instrument is confirmed. So is the inferiority of targeting through capital income taxation.

Now we investigate an alternative specification for the conduct of monetary policy; instead of interest-rate rules, we introduce a constant money-growth rate such as:

$$
\hat{m}_{t}=\mu \hat{m}_{t-1}
$$

The fiscal side remains the same as in the previous case. Table 7 shows the welfare results. Again, each line - corresponding to a different fiscal policy instruments - reports the combination of the policy rule parameters yielding the highest welfare configuration with respect to the proper benchmark. This time the coefficients subject to grid search are merely two: the money growth rate $(\mu)$ and the feedback coefficient of the fiscal instruments to the stock of public debt $(v)$. In case of distortionary taxation a constant money supply rule is always optimal (since there's no growth in this model), and the lowest welfare loss is achieved when it is accompanied by productive government spending targeting. Under taxation targeting, the only case of non-zero response to public debt is obtained under capital income taxation (with an elasticity of 0.3 ).

Table 8 is particularly important, as it reports the unconditional welfare measures - again for each fiscal instrument - associated with different a different degree of distortions in the model economy. Two results are noteworthy, one 'horizontal' and the other 'vertical' in terms of visualization of the table. The 'horizontal' result is that, ceteris paribus, the distortions arising from the presence of monopolistic competition and, although to a lesser extent, from the presence of money are the most relevant. Moving from price flexibility to price rigidity (within a monopolistic competition framework), on the other hand, does not deliver per se any additional welfare losses. On the other hand, a 'vertical' reading of Table 8 delivers a fairly homogenous welfare ranking: focusing on distortionary taxation, in cashless economies productive government spending targeting yields the lowest welfare loss, followed by consumption taxation and then by government consumption targeting. In monetary economies, instead, labour taxation (followed by consumption taxation) is the optimal configuration.

\subsection{Impulse response functions}

We also calculated impulse response functions - meant as first-order approximation of deviations from the deterministic steady state - of selected variables to productivity and money-demand shocks ${ }^{7}$ under different fiscal policy instruments. They are calculated based on welfare-optimizing parametrization. Figures 1-7 report the plots, with the upper panel showing the technology shock and the lower panel the monetary one.

The dashed lines indicate the cashless economy, and the circled lines refer to a positive money demand. After a positive technology shock, output and consumption increase under any targeting instrument, as standard. Inflation decreases and as a result nominal interest rate also decreases,

\footnotetext{
${ }^{7}$ Obviously the latter involves the presence of a non-zero money demand, whereas in the former we consider both specifications.
} 
since the feedback coefficient of the monetary policy rule on inflation is bigger that the one on output. It is interesting to note, in monetary economies, a significant liquidity effect, captured by the relevant increase in money holdings. Kim (2000) and Sims (1998) argue that such a strong liquidity effects is made possible by the substantial amount of nominal and real rigidities in the underlying structure of the model. While impulse response function retain the standard qualitative effects under any targeting, we can emphasize the different quantitative response of endogenous variables which are subject to distortionary taxation. With, alternatively, consumption, capital income and wage as fiscal instruments we observe negative effect on the response of, respectively, aggregate consumption, capital stock and hours worked to the positive productivity impulse.

\section{Conclusion}

In times of pressing need of fiscal consolidation, the relative desiderability of different fiscal policy instruments deserves particular attention. We provided statistical evidence that in its first decade fiscal policy in the Euro Area has followed a debt-stabilizing approach, reducing primary deficit after a debt shock. However, whether this stance is welfare maximizing - and, most of all, which side the adjustment should be implemented on - is still an open question. In this paper we built a large-scale DSGE model with a considerable number of imperfections and attempted to provide a welfare comparison of alternative fiscal policy tools according to different monetary policy stances. Consistently with theoretical literature and the real world policy environment, fiscal policy targets the accumulation of public debt, by increasing (decreasing) tax rates (government spending) in response to fiscal imbalances. Our results show that employing productive government expenditure as fiscal instrument in the feedback rule on debt is actually Pareto-improving under active interest-rate- based monetary policy in a cashless economy. Other instruments - particularly capital income taxation - lead instead to more consistent welfare losses. Modification of the economic environment such as non-zero money demand in the cashless economy or money supply-based monetary rules still preserve the qualitative properties of our welfare ranking, pointing towards a relative desirability of productive expenditure-based fiscal adjustments rather than the active utilization of distortionary tax instruments.

The general validity of such a conclusion might certainly be questioned by a more accurate analysis, capable of including key aspect that we were forced to leave out here, such a deeper consideration of the interactions between spending and revenue components of fiscal policy or a more precise investigation of non-Keynesian effects. A possible further step might incorporate some of the above suggestions so to be able to tackle into a DSGE framework more complex issues such as non-linearities in fiscal policy effects of the size of government spending multipliers. 


\section{References}

Alesina, A., And S. Ardagna (2009): "Large Changes in Fiscal Policy: Taxes versus Spending," unpublished manuscript.

Alesina, A., and R. Perotti (1997): "Fiscal Adjustments in OECD Countries: Composition and Macroeconomic Effects," IMF Staff Papers, 44.

Anderson, G., A. T. Levin, and E. Swanson (2004): "Higher-Order Perturbation Solutions to Dynamic, Discrete-Time Rational Expectations Models," unpublished manuscript, Federal Reserve Board.

Andrés, J., D. López-Salido, and J. Vallés (2001): "Money in an Estimated Business Cycle Model of the Euro Area," Bank of Spain Working Paper, 121.

Bayoumi, T., D. Laxton, and P. Pesenti (2004): "Benefits and Spillovers of Greater Competition in Europe," NBER Working Paper, 10416.

Bilbie, F. (2009): "Limited Asset Markets Participation, Monetary Policy and (inverted) Keynesian Logic," unpublished manuscript.

Blanchard, O. (1985): "Debt, Deficits and Finite Horizons," Journal of Political Economy, 93(2), 223-247.

Born, H. (1995): "The Sustainability of Budget Deficits in a Stochastic Economy," Journal of Money, Credit and Banking, 27, 257-271.

Brand, C., And N. Cassola (2004): "A Money Demand System for Euro Area M3," Applied Economics, 36, 817-838.

Brand, C., D. Gerdesmeier, and B. Roffia (2002): "Estimating the Trend of M3 Income Velocity Underlying the Reference Value for Monetary Growth," ECB Occasional Paper Series, 3.

C., L., And L. V. Thadden (2008): "Monetary and Fiscal Policy Interactions in a New Keynesian Model with Capital Accumulation and non-Ricardian Consumers," Journal of Economic Theory, 140(1), 279-313.

Calvo, G. (1983): "Staggered Prices in a Utility Maximizing Framework," Journal of Monetary Economics, 12, 383-398.

Canzoneri, M., R. Cumby, and B. Diba (2001): "Is the Price Level Determined by the Needs of Fiscal Solvency?," American Economic Review, 91(5), 1221-1238.

Chadha, R., and C. Nolan (2007): "Optimal and Simple Rules for the Conduct of Monetary and Fiscal Policy," Journal of Macroeconomics, 29, 665-689.

Davig, T., And E. Leeper (2005): "Fluctuating Macro Policies and the Fiscal Theory," unpublished manuscript. 
Edge, R., And J. Rudd (2002): "Taxation and the Taylor principle," Finance and Economics Discussion Series 51.

Galì, J., J. Lopez-Salido, and J. Vallès (2004): "Rule of Thumb Consumers and the Design of Interest Rate Rules," Journal of Money, Credit and Banking, 36(4), 739-764.

Giavazzi, F., and M. Pagano (1990): "Can Severe Fiscal Contractions Be Expansionary ? Tales of Two Small European Countries," in NBER Macroeconomics Annual, MIT Press. MIT Press.

Ireland, P. N. (2001): "Sticky-Price Models of the Business Cycle: Specification and Stability," Journal of Monetary Economics.

KIm, J. (2003): "Functional Equivalence Between Intertemporal and Multisectoral Investment Adjustment Costs," Journal of Economic Dynamics and Control, 27(4), 533-549.

Kim, J., And S. H. Kim (2003a): "Spurious Welfare Reversals in International Business Cycle Models," Journal of International Economics, 60(2), 471-500.

- (2003b): "Welfare Effects of Tax Policy in Open Economies: Stabilization and Cooperation," unpublished manuscript, Tufts University.

Kollmann, R. (2003): "Welfare Maximizing Fiscal and Monetary Policy Rules," unpublished manuscript, University of Bonn.

Leeper, E. (1991): "Equilibria under 'Active' and 'Passive' Monetary and Fiscal Policies," Journal of Monetary Economics, 27, 129-147.

Leith, C., And S. Wren-Lewis (2000): "Interactions between Monetary and Fiscal Policy Rules," Economic Journal, 110, 93-108.

Linnemann, L. (2006): "Interest Rate Policy, Debt, and Indeterminacy with Distortionary Taxation," Journal of Economic Dynamics and Control, 30, 487-510.

Linnemann, L., and A. Schabert (2004): "Can Fiscal Spending Stimulate Private Consumption?," Economic Letters, 82.

Paustian, M. (2003): "Gains from Second-Order Approximations," unpublished manuscript, University of Bonn.

Prescott, E. C. (2003): "Why Do Americans Work So Much More than Europeans?" Staff Report, Federal Reserve Bank of Minneapolis, 321.

Railavo, J. (2004): "Stability Consequences of Fiscal Policy Rules," Bank of Finland Discussion Paper, 1.

Rotemberg, J. (1982): "Monopolistic Price Adjustment and Aggregate Output," Review of Economic Studies, 49, 517-531.

Schmitt-Grohé, S., and M. Uribe (2004a): "Optimal Fiscal and Monetary Policy Under Imperfect Competition," forthcoming in the Journal of Macroeconomics. 
(2004b): "Optimal Operational Monetary Policy in the Christiano-Eichenbaum-Evans Model of the U.S. Business Cycle," unpublished manuscript, Duke University.

(2004c): "Solving Dynamic General Equilibrium Models Using a Second-Order Approximation to the Policy Function," Journal of Economic Dynamics and Control, 28(3), $755-775$.

(2007): "Optimal Simple and Implementable Monetary and Fiscal Rules," Journal of Monetary Economics, 54, 1702-1725.

Sims, C. (1994): "A Simple Model for Study of the Determination of the Price Level and The Interaction of Monetary and Fiscal Policy," Economic Theory, 4, 381-99.

(1998): "The Precarious Fiscal Foundations of EMU," unpublished manuscript, Princeton University.

Smets, F., And R. Wouters (2003): "An Estimated Stochastic Dynamic General Equilibrium Model of the Euro Area," Journal of the European Economic Association, 1(5), 1123-1175.

Sutherland, A. (2002): "A Simple Second-Order Solution Method for Dynamic General Equilibrium Models," unpublished manuscript, University of St Andrews.

Woodford, M. (1994): "Monetary Policy and Price Level Determinacy in a Cash-In-Advance Economy," Economic Theory, 25, 345-380.

Woodford, M. (2003): Interest and Prices: Foundations of a Theory of Monetary Policy. Princeton University Press. 
Figure 1: Impulse responses
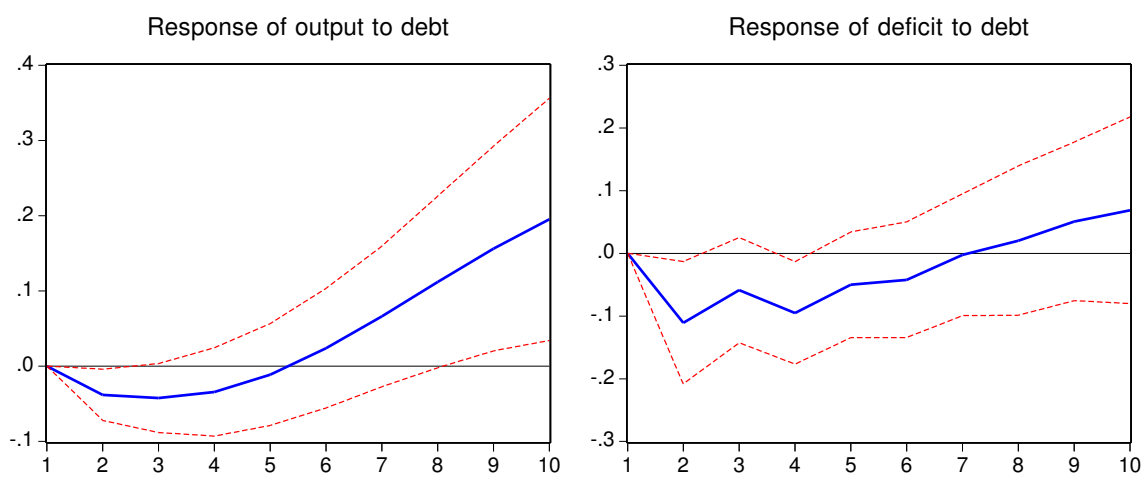

Legend: The error bands are computed according to Antithetic Accelerated Monte-Carlo 10000 simulations 
Figure 2: Impulse responses

\section{Response of Deficit to one st. dev. innovations}
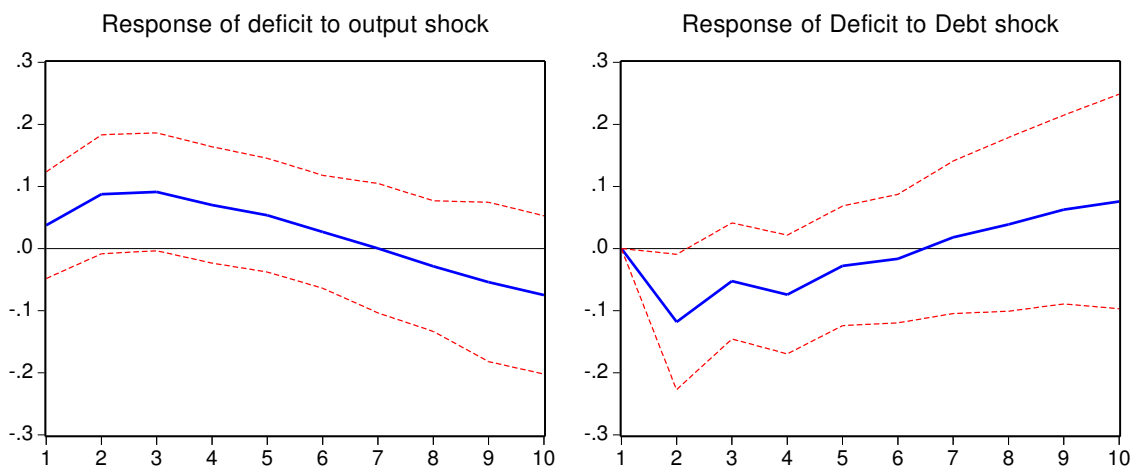

Legend: The error bands are computed according to Antithetic Accelerated Monte-Carlo 10000 simulations

Figure 3: Impulse responses

Response of debt to one st. dev. output innovation

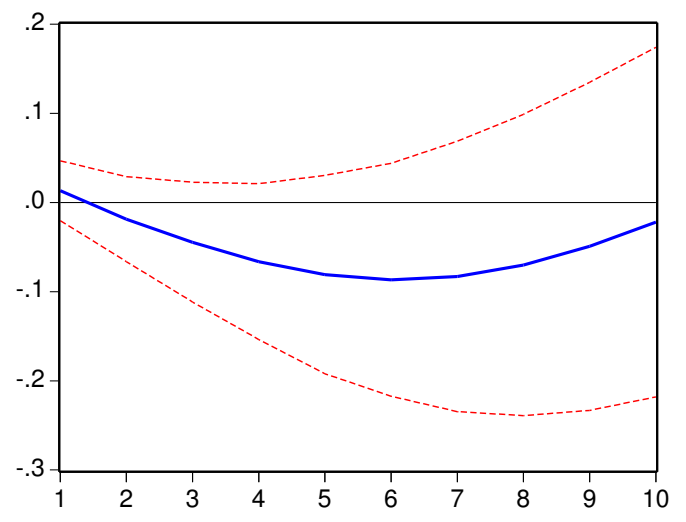

Legend: The error bands are computed according to Antithetic Accelerated Monte-Carlo 10000 simulations 
Figure 4: Impulse responses with lump-sum taxes as the fiscal-policy instrument, one std productivity shock
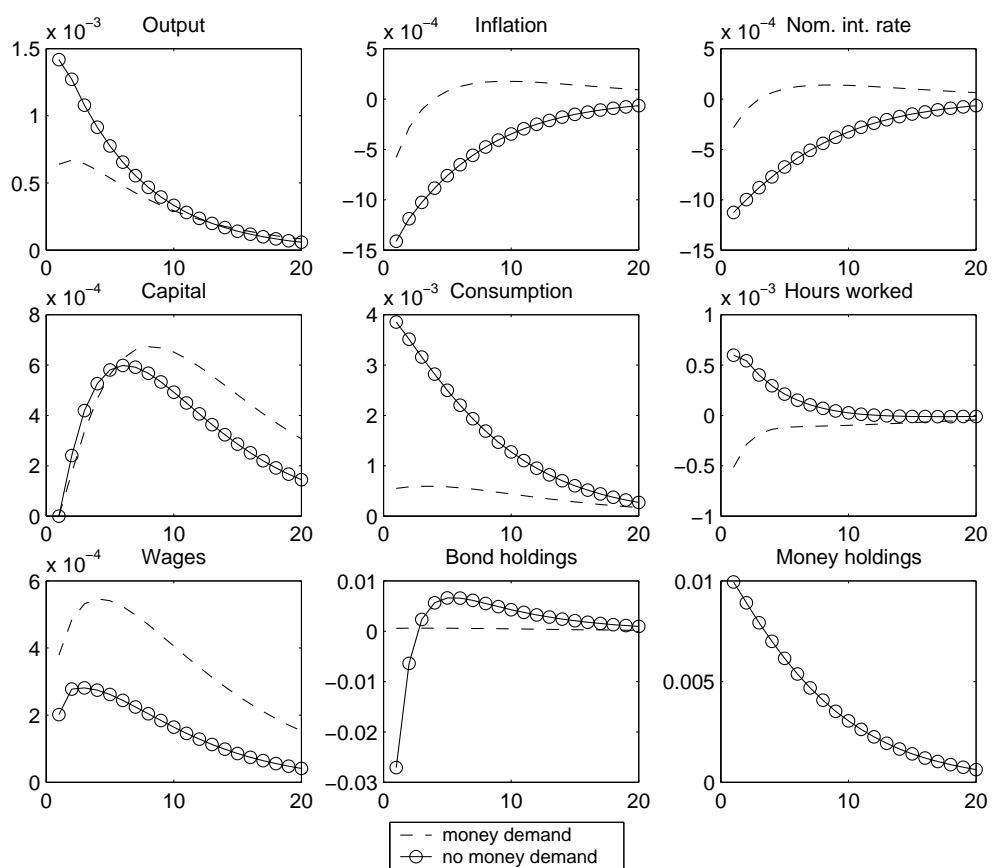

Legend: Circles and dashed lines denote the models with and without money demand, respectively. The plots report first-order approximations of deviations from the deterministic steady states. 
Figure 5: Impulse responses with constant steady-state taxation, one std productivity shock
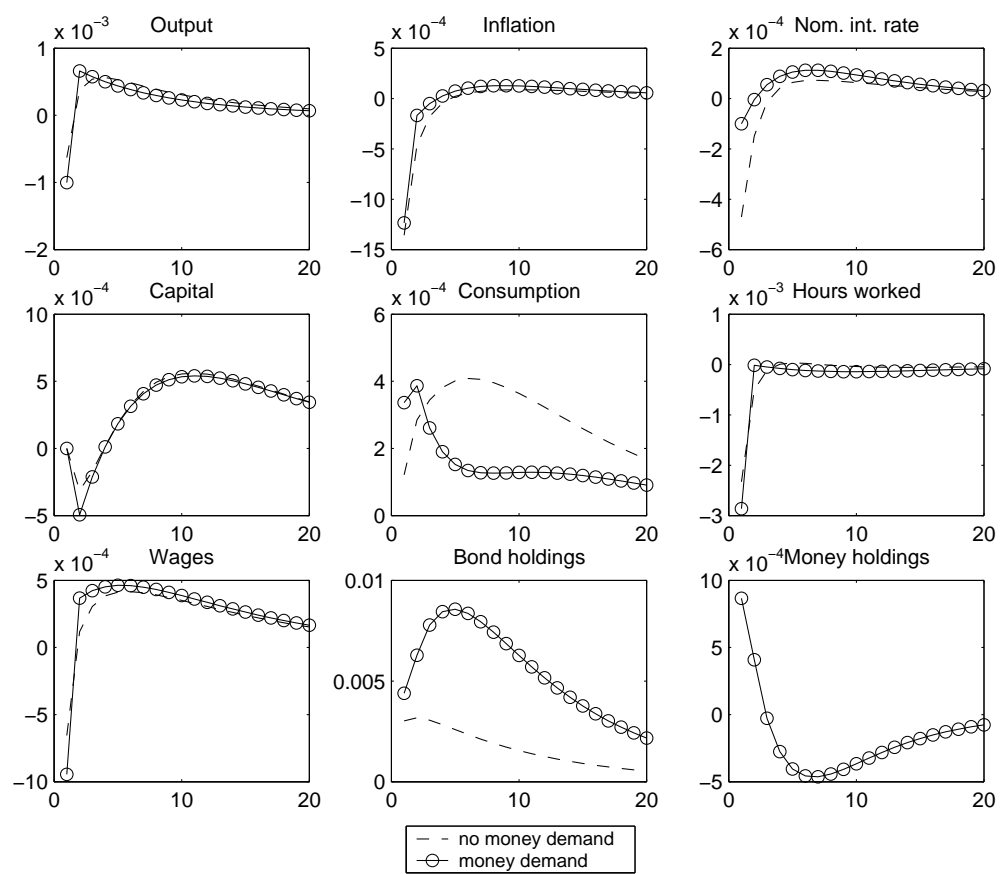

Legend: Circles and dashed lines denote the models with and without money demand, respectively. The plots report first-order approximations of deviations from the deterministic steady states. 
Figure 6: Impulse responses with consumption taxes as the fiscal-policy instrument, one std productivity shock
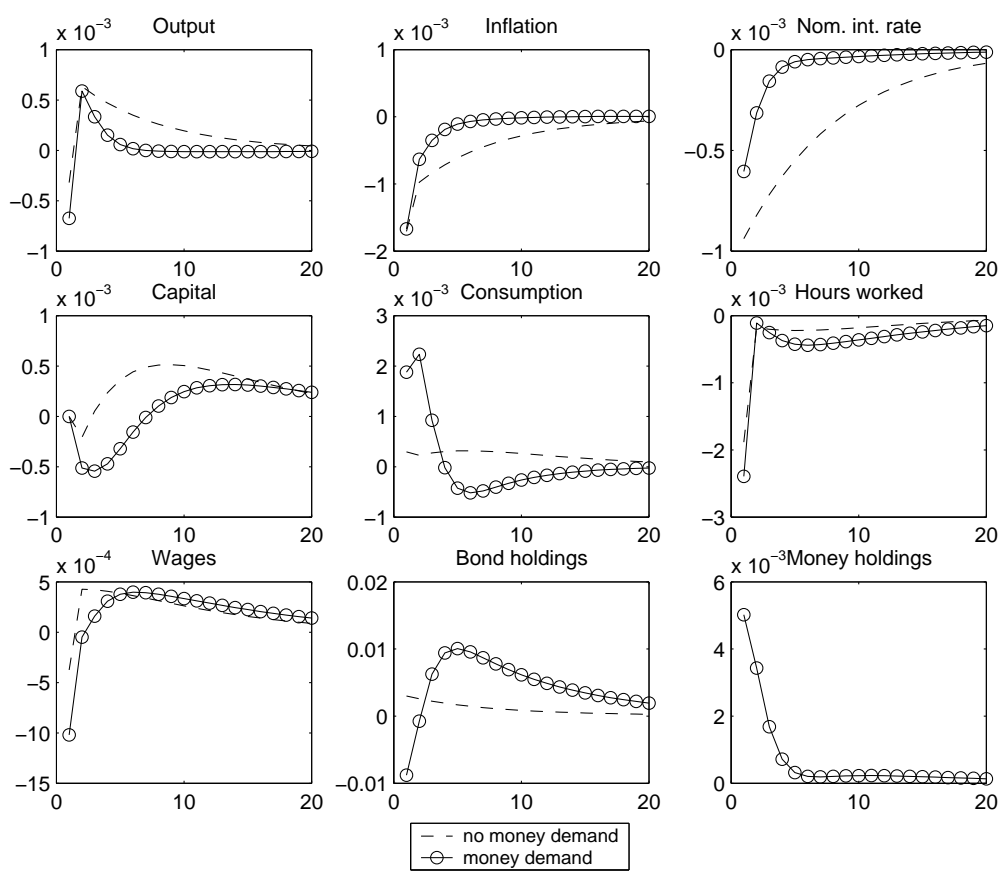

Legend: Circles and dashed lines denote the models with and without money demand, respectively. The plots report first-order approximations of deviations from the deterministic steady states. 
Figure 7: Impulse responses with capital-income taxes as the fiscal-policy instrument, one std productivity shock
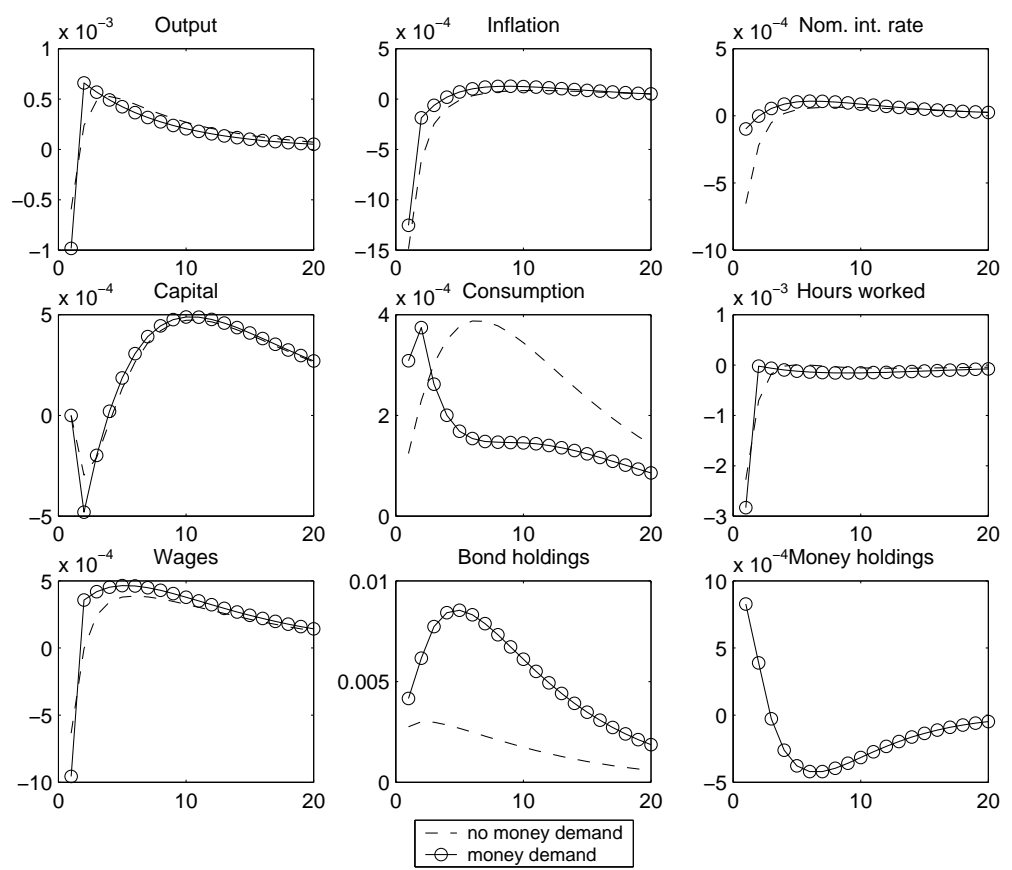

Legend: Circles and dashed lines denote the models with and without money demand, respectively. The plots report first-order approximations of deviations from the deterministic steady states. 
Figure 8: Impulse responses with labour-income taxes as the fiscal-policy instrument, one std productivity shock
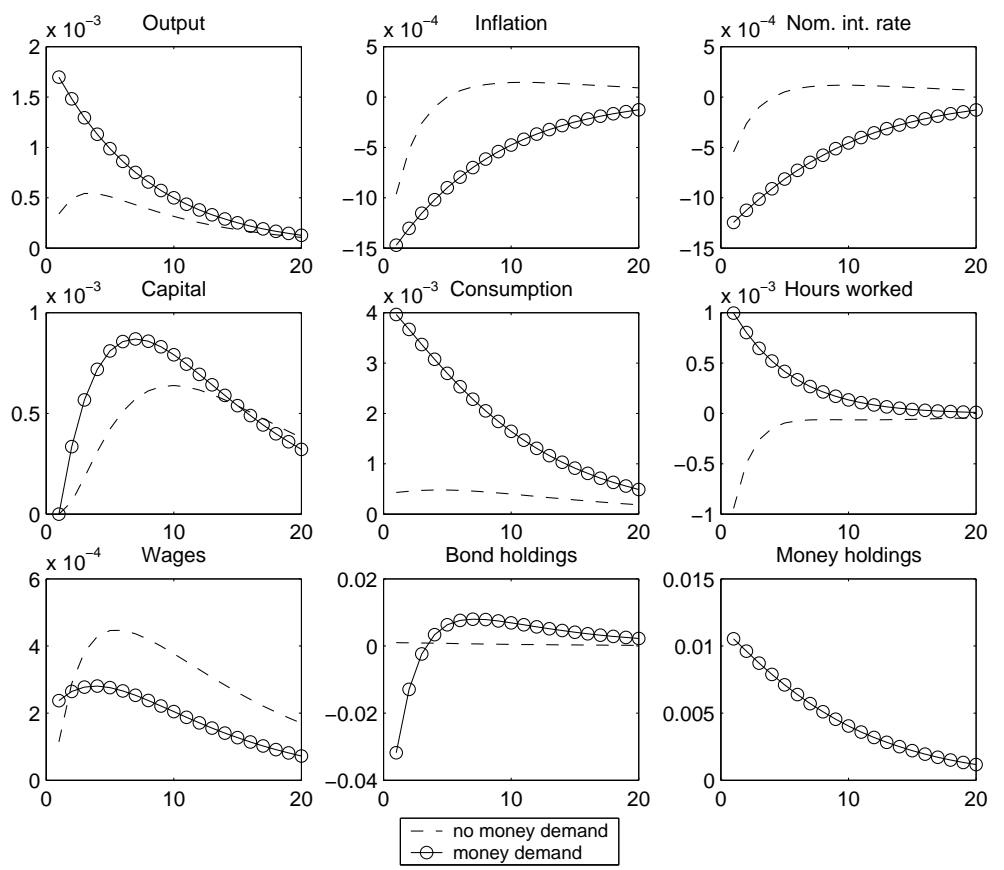

Legend: Circles and dashed lines denote the models with and without money demand, respectively. The plots report first-order approximations of deviations from the deterministic steady states. 
Figure 9: Impulse responses with government consumption as the fiscal-policy instrument, one std productivity shock
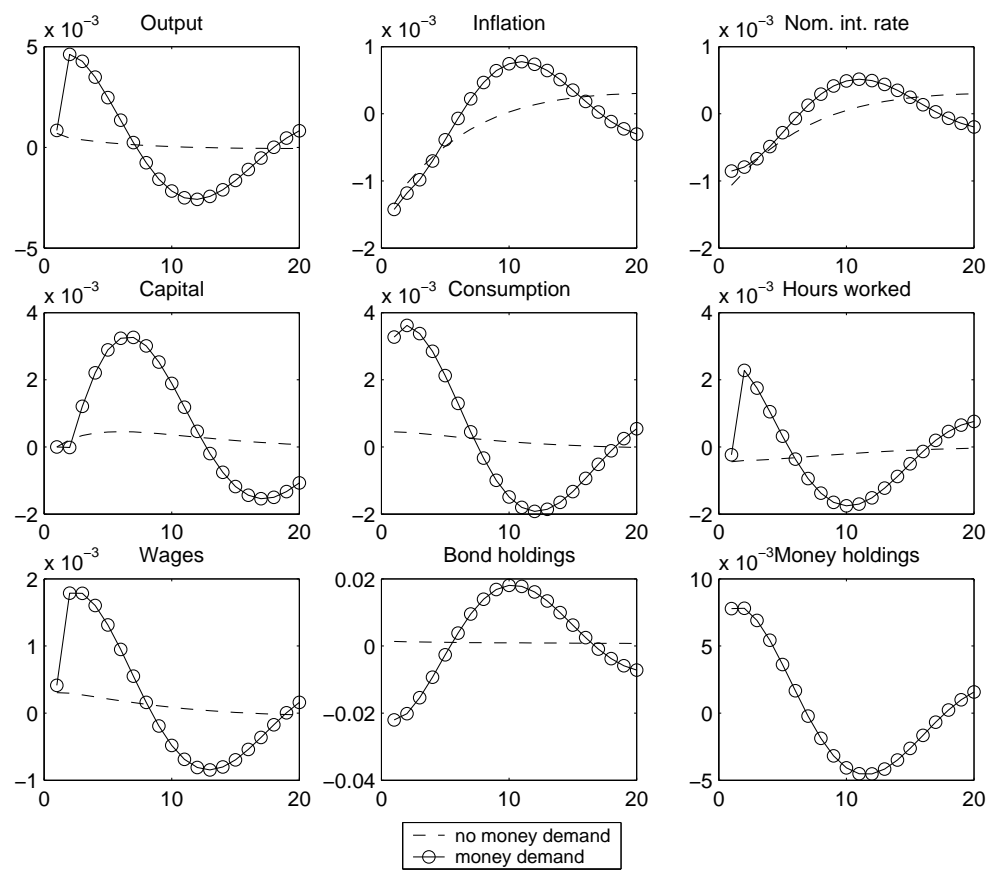

Legend: Circles and dashed lines denote the models with and without money demand, respectively. The plots report first-order approximations of deviations from the deterministic steady states. 
Figure 10: Impulse responses with productive government spending as the fiscal-policy instrument, one std productivity shock
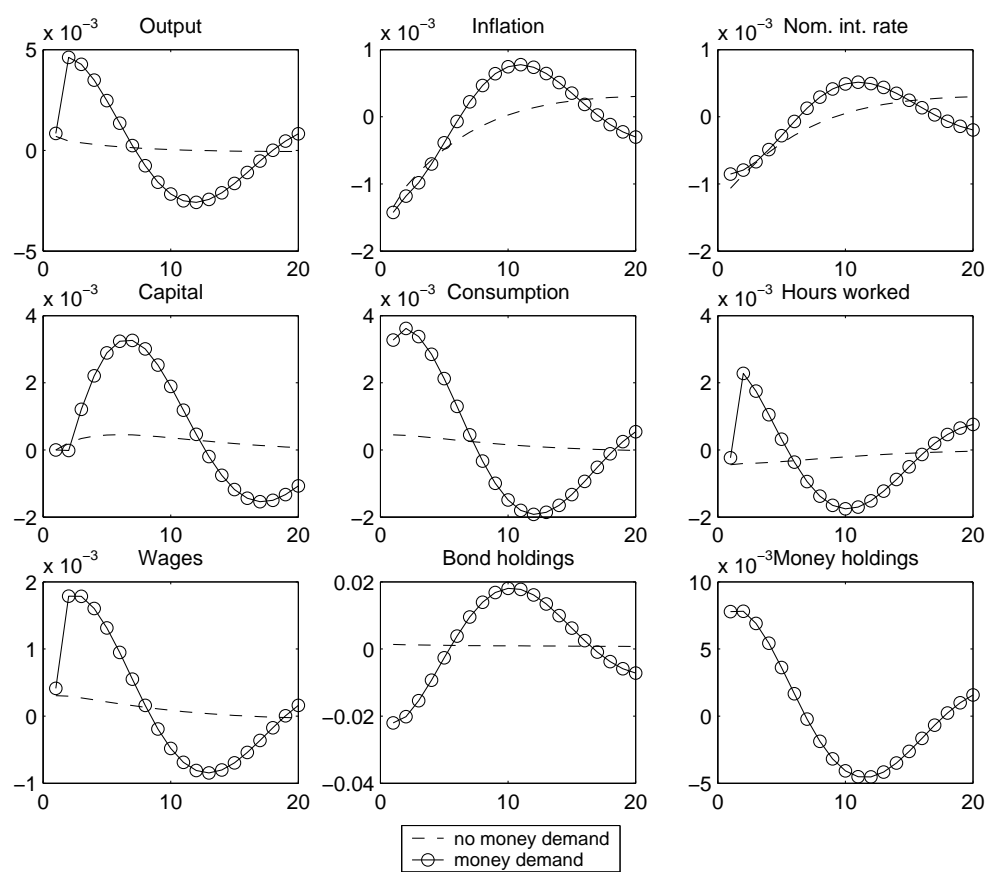

Legend: Circles and dashed lines denote the models with and without money demand, respectively. The plots report first-order approximations of deviations from the deterministic steady states. 
Table 1: Evolution of Debt/GDP ratio, major industrialized Countries

\begin{tabular}{lcc}
\hline \hline Country & Debt/GDP 2007 & Debt/GDP 2010 \\
\hline Ireland & 24.80 & 79.70 \\
Luxembourg & 7 & 14.50 \\
Spain & 36.20 & 62.30 \\
United Kingdom & 44.15 & 71 \\
United States & $63.05 \%$ & 91.57 \\
Netherlands & 45.70 & 63.10 \\
Finland & 35.10 & 45.70 \\
Portugal & 63.60 & 81.50 \\
Denmark & 26.84 & 33.66 \\
Germany & 65.10 & 78.70 \\
Belgium & 83.90 & 100.90 \\
Japan & 167.10 & 193.97 \\
Italy & 104.10 & 116.10 \\
\hline \hline
\end{tabular}


Table 2: Descriptive Statistics: Public Finance Variables

\begin{tabular}{lccc}
\hline \hline & Debt & Public Expenditure & Tax Revenue \\
\hline Mean & $2.64 \mathrm{E}-13$ & 0.001969 & 0.003311 \\
Median & $-4.21 \mathrm{E}-06$ & 0.001297 & -0.023953 \\
Std. Dev. & 0.267702 & 0.053201 & 0.163378 \\
Skewness & 0.310057 & 0.365543 & 0.189218 \\
Kurtosis & 4.092 & 3.525 & 2.224 \\
Jarque-Bera & 2.90 & 1.385 & 1.270 \\
& $(0.2595)$ & $(0.50)$ & $(0.529)$ \\
\hline \hline
\end{tabular}


Table 3: Autocorrelations

\begin{tabular}{lccc}
\hline \hline lag & Debt & Public Expenditure & Tax Revenue \\
\hline 1 & 0.552 & 0.262 & 0.576 \\
2 & 0.344 & 0.090 & 0.472 \\
3 & 0.126 & 0.059 & 0.303 \\
4 & -0.086 & 0.020 & 0.142 \\
7 & -0.376 & -0.035 & -0.255 \\
8 & -0.374 & -0.205 & -0.382 \\
9 & -0.358 & -0.167 & -0.400 \\
10 & -0.305 & -0.058 & -0.420 \\
16 & 0.011 & -0.186 & -0.191 \\
\hline \hline
\end{tabular}




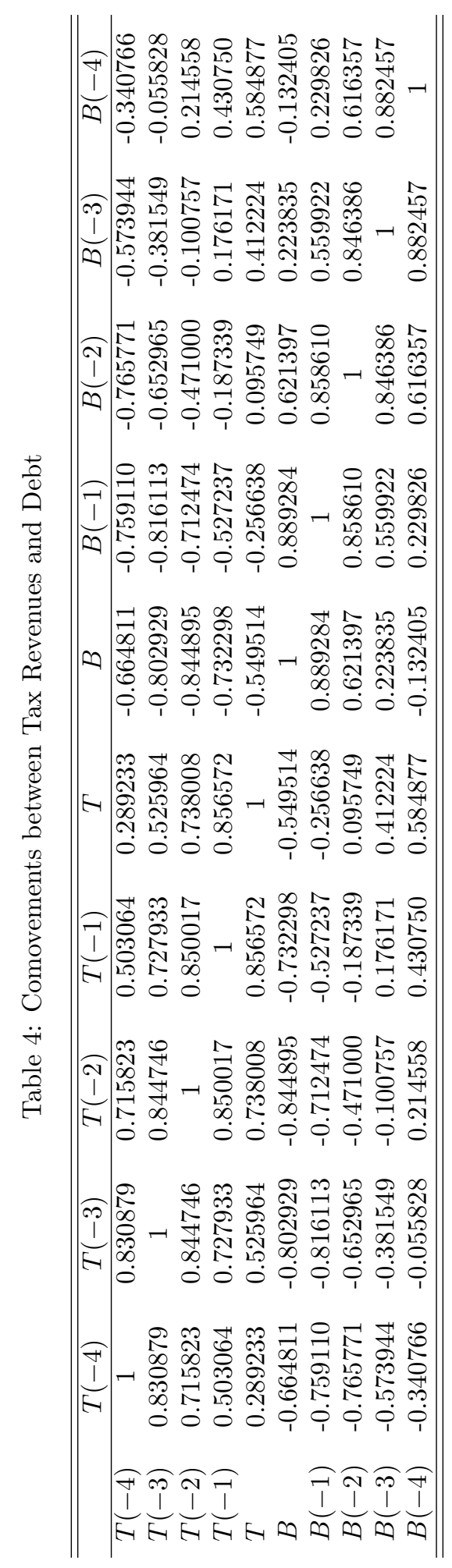




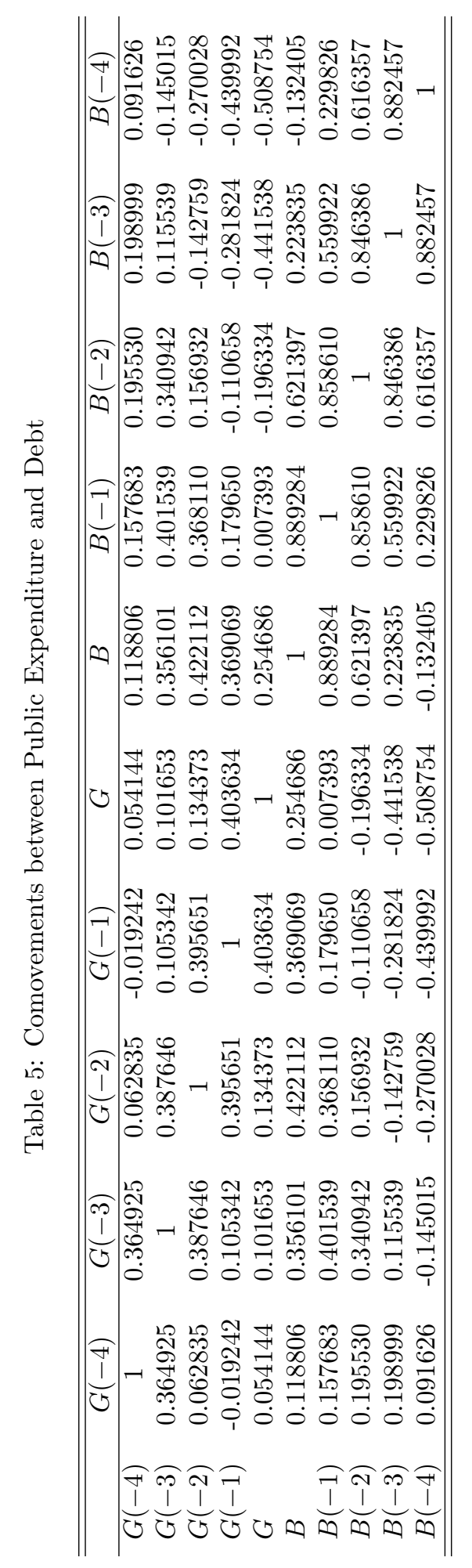


Table 6: Calibration of the model

\begin{tabular}{lcc}
\hline \hline Description & Parameter & Value \\
\hline Discount factor of households & $\beta$ & 0.993 \\
Intertemporal elasticity of substitution & $1 / \gamma_{2}$ & 0.667 \\
CES weight in the utility function & $\gamma_{1}$ & 0.358 \\
Parameter of transaction cost function & $a$ & 2.100 \\
Parameter of transaction cost function & $b$ & 0.030 \\
Persistence transaction cost shock & $\rho_{\psi}$ & 0.962 \\
Steady state of transaction cost shock & $\bar{\psi}$ & 1.000 \\
Standard dev. of transaction cost shock & $\sigma_{\psi}$ & 0.005 \\
Rate of capital depreciation & $\delta$ & 0.100 \\
\hline Elasticity of substitution of intermediate goods & $\theta$ & 5.200 \\
Capital elasticity of intermediate output & $\alpha$ & 0.300 \\
Productive government spending elasticity & $\zeta$ & 0.100 \\
Persistence of productivity shock & $\rho_{z}$ & 0.820 \\
Steady state of productivity shock & $\bar{z}$ & 1.000 \\
Standard dev. of productivity shock & $\sigma_{z}$ & 0.001 \\
Adjustment cost parameter of prices & $\phi_{p}$ & 10.00 \\
\hline Steady-state average capital tax & $\bar{\tau}^{k}$ & 0.266 \\
Steady-state average consumption tax & $\bar{\tau}^{c}$ & 0.163 \\
Steady-state average labor tax & $\bar{\tau}^{\ell}$ & 0.403 \\
Government consumption-output ratio & $\bar{g}^{c} / \bar{y}$ & 0.346 \\
Productive public spending-output ratio & $\bar{g}^{p} / \bar{y}$ & 0.040 \\
\hline Parameter on zero bound for $R_{t}$ & $\kappa$ & 2 \\
Parameter scaling exogenous shocks & $\sigma$ & 1 \\
\hline \hline
\end{tabular}


Table 7: Coverage of determinacy regions as a percentage of grid points

\begin{tabular}{lcc}
\hline \hline Fiscal instrument & No money & Money \\
\hline Lump-sum taxation & 77.31 & 59.15 \\
& $(0)$ & $(0)$ \\
& {$[0.14]$} & {$[6.06]$} \\
Constant taxation & 15.14 & 21.14 \\
& $(0)$ & $(0)$ \\
& {$[0.99]$} & {$[10.24]$} \\
Consumption taxes & 77.31 & 79.81 \\
& $(0)$ & $(0)$ \\
& {$[0.14]$} & {$[4.59]$} \\
Labour-income taxes & 77.45 & 59.54 \\
& $(0)$ & $(0)$ \\
& {$[0.01]$} & {$[5.42]$} \\
Capital-income taxes & 16.01 & 41.97 \\
& $(0.01)$ & $(0)$ \\
& {$[1.71]$} & {$[12.77]$} \\
& 77.36 & 79.98 \\
Gov. consumption & $(0.01)$ & $(0)$ \\
& {$[0.09]$} & {$[1.07]$} \\
& 18.81 & 49.39 \\
Prod. gov. spending & $(0.01)$ & $(0)$ \\
& {$[0.60]$} & {$[18.82]$} \\
\hline \hline
\end{tabular}

Legend: Figures in round and square brackets indicate the percentages of grid points where the zero-bound 30 on nominal interest rates and the public-debt condition 29 do not hold respectively. 


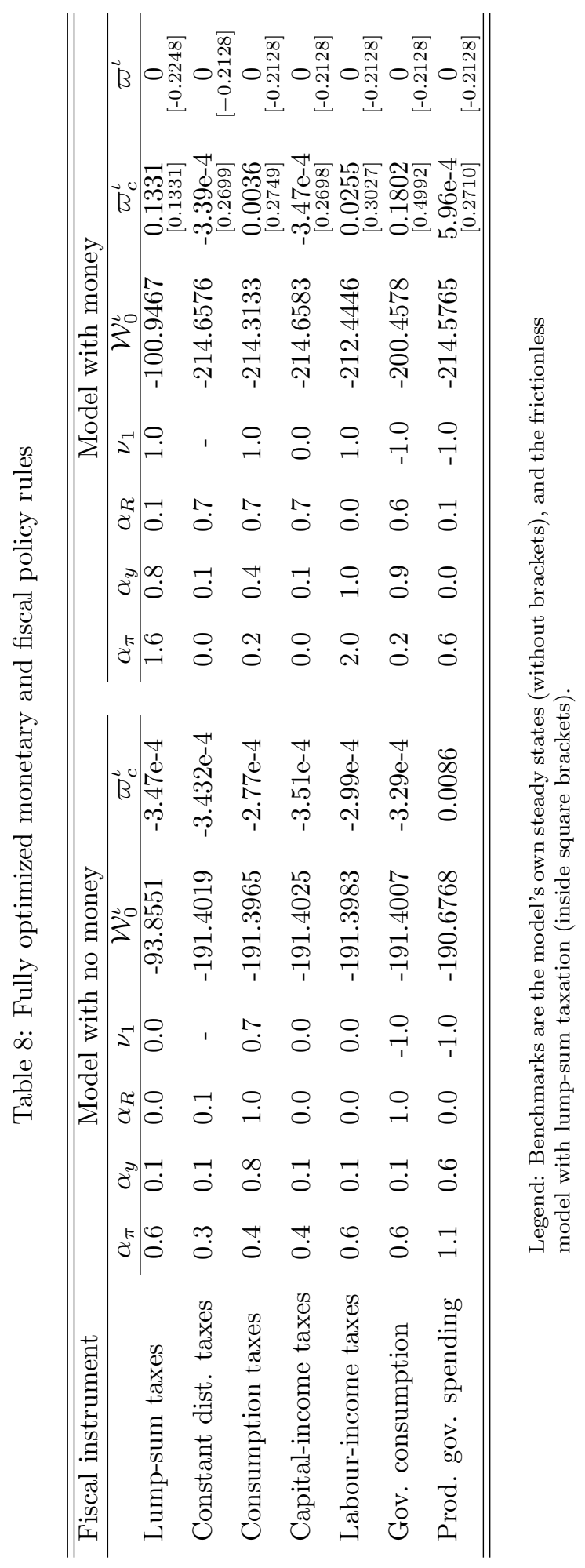




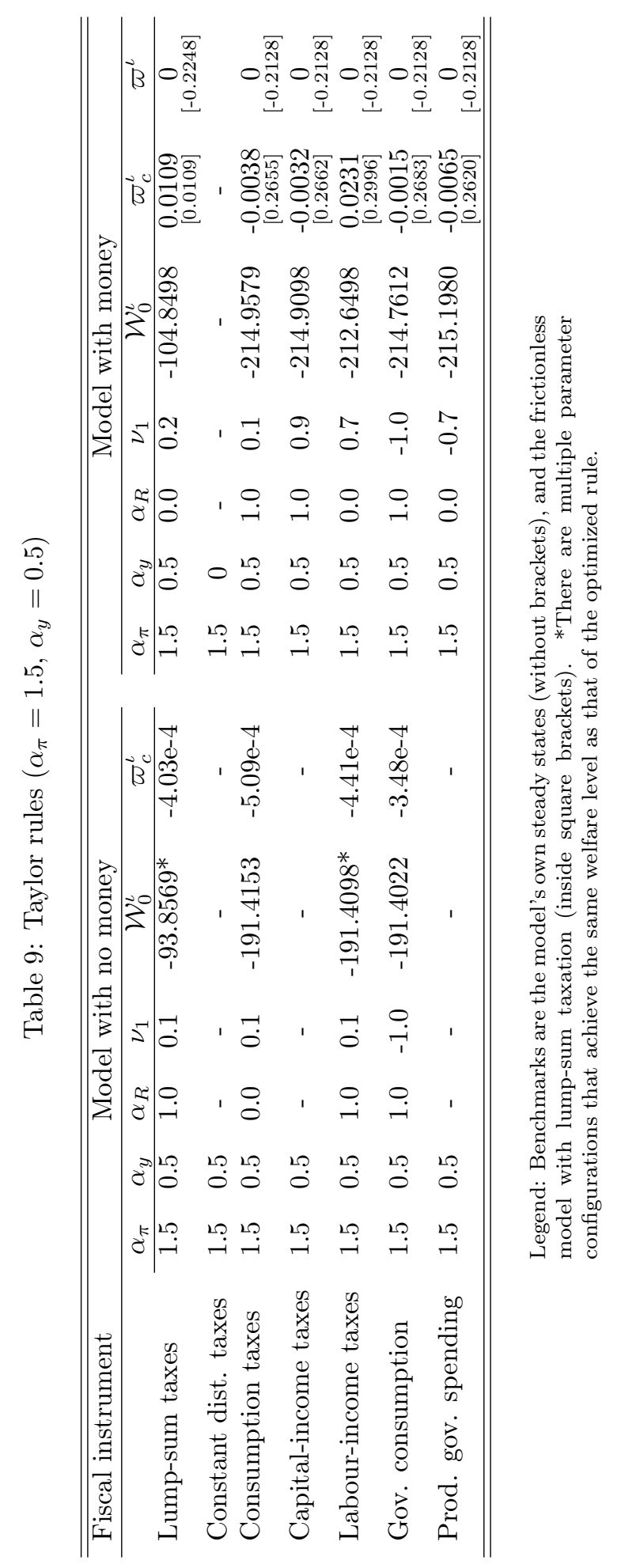




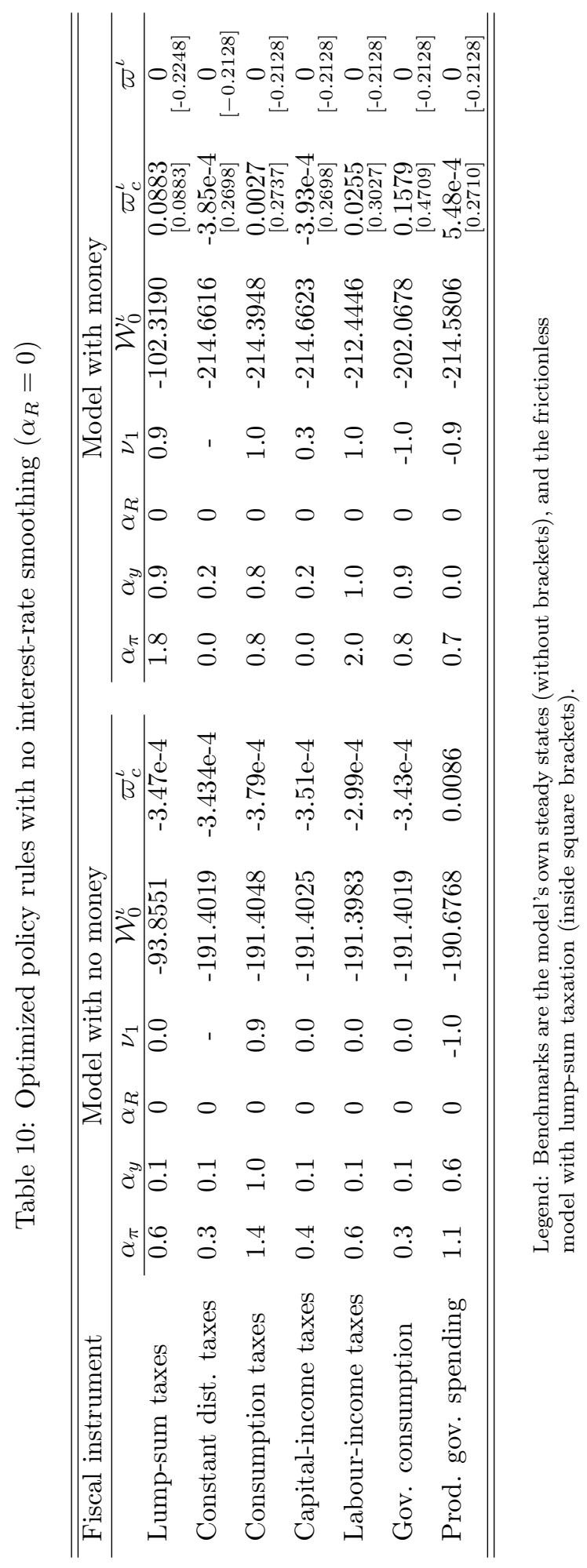




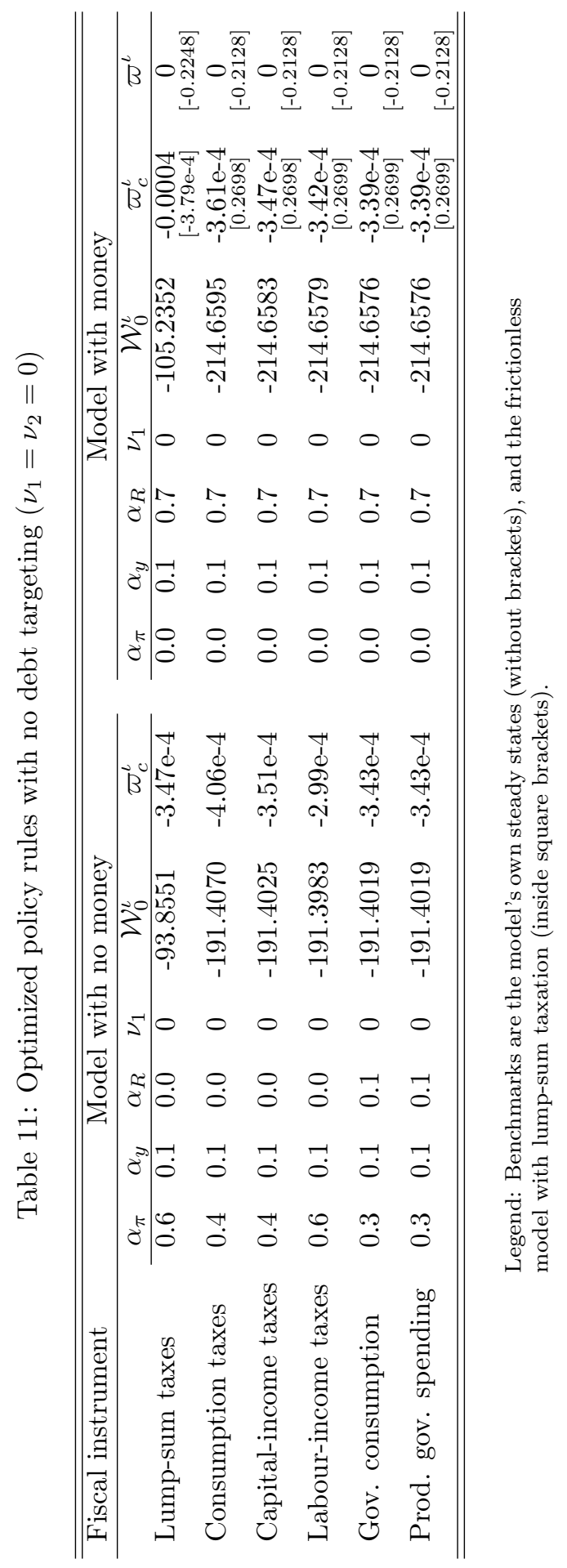


Table 12: Optimized money-growth rules

\begin{tabular}{|c|c|c|c|c|c|}
\hline Fiscal instrument & $\mu$ & $\nu$ & $\mathcal{W}_{0}^{\iota}$ & $\varpi_{c}^{\iota}$ & $\varpi^{\iota}$ \\
\hline Lump-sum taxes & 0.5 & 0.0 & -105.2945 & & $\begin{array}{c}0 \\
{[-0.2247]}\end{array}$ \\
\hline Constant dist. taxes & 0.0 & - & -214.7549 & & {$\left[\begin{array}{c}0 \\
{[-0.2128]}\end{array}\right.$} \\
\hline Consumption taxes & 0.0 & 0.0 & -214.7783 & & $\begin{array}{c}0 \\
{[-0.2128]}\end{array}$ \\
\hline Capital-income taxes & 0.0 & 0.3 & -214.7546 & & $\begin{array}{c}0 \\
{[-0.2128]}\end{array}$ \\
\hline Labour-income taxes & 0.0 & 0.0 & -214.7800 & & $\begin{array}{c}0 \\
{[-0.2128]}\end{array}$ \\
\hline Gov. consumption & 0.0 & 0.0 & -214.7549 & $\begin{array}{r}-0.0015 \\
{[0.2684]}\end{array}$ & $\begin{array}{c}0 \\
{[-0.2128]}\end{array}$ \\
\hline Prod. gov. spending & 0.0 & -0.1 & -214.7512 & $\begin{array}{c}-0.0014 \\
{[0.2685]}\end{array}$ & {$\left[\begin{array}{c}0 \\
{[-0.2128]}\end{array}\right.$} \\
\hline
\end{tabular}

Legend: Benchmarks are the model's own steady states (without brackets), and the frictionless model with lump-sum taxation (inside square brackets).

Note: There are multiple parameter configurations that achieve the same welfare level as that of the optimized rule. 
Table 13: Unconditional welfare costs of Taylor rules with interest-rate smoothing

\begin{tabular}{lcccccc}
\hline \hline & \multicolumn{2}{c}{ Perfect competition } & \multicolumn{3}{c}{ Monopolistic competition } \\
\cline { 2 - 6 } Fiscal instrument & No money & Money & No money & Money & No money & Money \\
\cline { 2 - 6 } & -0.8324 & -0.9616 & -0.9422 & -1.0574 & -0.9421 & -1.0572 \\
& $(-5.06 \mathrm{e}-4)$ & $(0.3317)$ & $(-5.21 \mathrm{e}-4)$ & $(0.2853)$ & $(-4.39 \mathrm{e}-4)$ & $(0.2864)$ \\
& {$[-3.06 \mathrm{e}-14]$} & {$[-0.2514]$} & {$[-3.06 \mathrm{e}-14]$} & {$[-0.2248]$} & {$[-3.06 \mathrm{e}-14]$} & {$[-0.2248]$} \\
Constant dist. taxes & -1.2403 & -1.4251 & -1.4141 & -1.5855 & -1.4140 & -1.5858 \\
& $(-5.48 \mathrm{e}-4)$ & $(0.2998)$ & $(-5.73 \mathrm{e}-4)$ & $(0.2703)$ & $(-3.32 \mathrm{e}-4)$ & $(0.2698)$ \\
& {$[-3.06 \mathrm{e}-14]$} & {$[-0.2305]$} & {$[-3.06 \mathrm{e}-14]$} & {$[-0.2127]$} & {$[-3.06 \mathrm{e}-14]$} & {$[-0.2127]$} \\
Consumption taxes & -1.2401 & -1.4251 & -1.4139 & -1.5849 & -1.4139 & -1.5835 \\
& $(-1.61 \mathrm{e}-4)$ & $(0.2998)$ & $(-1.88 \mathrm{e}-4)$ & $(0.2715)$ & $(-2.58 \mathrm{e}-4)$ & $(0.2743)$ \\
& {$[-3.06 \mathrm{e}-14]$} & {$[-0.2305]$} & {$[-3.06 \mathrm{e}-14]$} & {$[-0.2127]$} & {$[-3.06 \mathrm{e}-14]$} & {$[-0.2127]$} \\
Capital-income taxes & -1.2403 & -1.4251 & -1.4141 & -1.5855 & -1.4140 & -1.5858 \\
& $(-5.26 \mathrm{e}-4)$ & $(0.2998)$ & $(-5.08 \mathrm{e}-4)$ & $(0.2703)$ & $(-3.27 \mathrm{e}-4)$ & $(0.2698)$ \\
& {$[-3.06 \mathrm{e}-14]$} & {$[-0.2305]$} & {$[-3.06 \mathrm{e}-14]$} & {$[-0.2127]$} & {$[-3.06 \mathrm{e}-14]$} & {$[-0.2127]$} \\
Labour-income taxes & -1.2403 & -1.4019 & -1.4141 & -1.5682 & -1.4140 & -1.5693 \\
& $(-5.40 \mathrm{e}-4)$ & $(0.3567)$ & $(-5.73 \mathrm{e}-4)$ & $(0.3051)$ & $(-3.37 \mathrm{e}-4)$ & $(0.3030)$ \\
& {$[-3.06 \mathrm{e}-14]$} & {$[-0.2305]$} & {$[-3.06 \mathrm{e}-14]$} & {$[-0.2127]$} & {$[-3.06 \mathrm{e}-14]$} & {$[-0.2127]$} \\
Gov. consumption & -1.2402 & -1.4251 & -1.4140 & -1.5855 & -1.4140 & -1.4749 \\
& $(-3.19 \mathrm{e}-4)$ & $(0.2998)$ & $(-3.62 \mathrm{e}-4)$ & $(0.2703)$ & $(-3.43 \mathrm{e}-4)$ & $(0.5136)$ \\
& {$[-3.06 \mathrm{e}-14]$} & {$[-0.2305]$} & {$[-3.06 \mathrm{e}-14]$} & {$[-0.2127]$} & {$[-3.06 \mathrm{e}-14]$} & {$[-0.2127]$} \\
Prod. gov. spending & -1.2402 & -1.4251 & -1.4136 & -1.5855 & -1.4074 & -1.5854 \\
& $(-3.80 \mathrm{e}-4)$ & $(0.2998)$ & $(2.09 \mathrm{e}-4)$ & $(0.2703)$ & $(0.0107)$ & $(0.2705)$ \\
& {$[-3.06 \mathrm{e}-14]$} & {$[-0.2305]$} & {$[-3.06 \mathrm{e}-14]$} & {$[-0.2127]$} & {$[-3.06 \mathrm{e}-14]$} & {$[-0.2127]$} \\
\hline \hline
\end{tabular}

Legend: Round and square brackets indicate, respectively, the unconditional welfare cost $\varpi_{u c}^{\iota}$ and the steady-state jump $\varpi^{\iota}$ with respect to the model with perfect competition, no money demand and lump-sum taxation. The remaining figures are $\mathcal{W}^{\iota}$. 


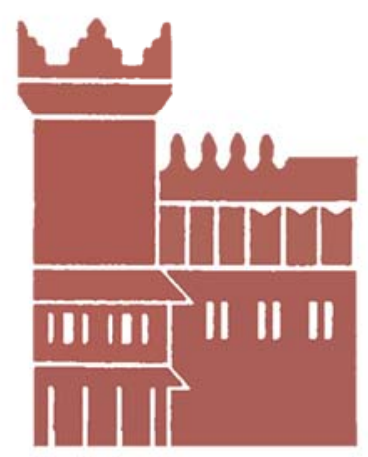

Alma Mater Studiorum - Università di Bologna DEPARTMENT OF ECONOMICS

Strada Maggiore 45

40125 Bologna - Italy

Tel. +39051 2092604

Fax +390512092664

http://www.dse.unibo.it 